\title{
Interannual Variations of the First Rainy Season Precipitation over South China
}

\author{
WEI GU \\ Laboratory for Climate Studies, National Climate Center, China Meteorological Administration, Beijing, China
}

LIN WANG

Center for Monsoon System Research, and State Key Laboratory of Numerical Modeling for Atmospheric Sciences and Geophysical Fluid Dynamics, Institute of Atmospheric Physics, Chinese Academy of Sciences, Beijing, China

ZENG-ZHEN HU

Climate Prediction Center, NOAA/NWS/NCEP, College Park, Maryland

\section{KAIMING HU}

Center for Monsoon System Research, and State Key Laboratory of Numerical Modeling for Atmospheric Sciences and Geophysical Fluid Dynamics, Institute of Atmospheric Physics, Chinese Academy of Sciences, Beijing, China

YONG LI

National Meteorological Center, China Meteorological Administration, Beijing, China

(Manuscript received 30 April 2017, in final form 11 July 2017)

\begin{abstract}
The first rainy season (FRS), also known as the presummer rainy season, is the first standing stage of the East Asian summer monsoon when over $40 \%$ of the annual precipitation is received over South China. Based on the start and end dates of the FRS defined by the China Meteorological Administration, this study investigates the interannual variations of the FRS precipitation over South China and its mechanism with daily mean data. The length and start/end date of the FRS vary year to year, and the average length of the FRS is 90 days, spanning from 6 April to 4 July. Composite analyses reveal that the years with abundant FRS precipitation over South China feature weakened anticyclonic wind shear over the Indochina Peninsula in the upper troposphere, southwestward shift of the western Pacific subtropical high, and anticyclonic wind anomalies over the South China Sea in the lower troposphere. The lower-tropospheric southwesterly wind anomalies are especially important because they help to enhance warm advection and water vapor transport toward South China, increase the lower tropospheric convective instability, and shape the pattern of the anomalous ascent over South China. It is further proposed that a local positive feedback between circulation and precipitation exists in this process. The variability of the FRS precipitation can be well explained by a zonal sea surface temperature (SST) dipole in the tropical Pacific and the associated Matsuno-Gill-type Rossby wave response over the western North Pacific. The interannual variability of both the SST dipole and the FRS precipitation over South China is weakened after the year 2000.
\end{abstract}

\section{Introduction}

A remarkable feature of the East Asian rainy season is its stepwise northward and eastward migration (Tao and Chen 1987). Accordingly, three standing stages of

Corresponding author: Lin Wang, wanglin@mail.iap.ac.cn the East Asian summer monsoon (EASM) are formed, known as the first rainy season (FRS; also as the presummer rainy season) over South China; the mei-yu/baiu/ changma over eastern China, Japan, and the Korean Peninsula; and the rainy season over north and northeast China (Ding and Chan 2005; Wang 2006; Huang et al. 2012). The FRS indicates the beginning of the 
rainy season in South China, and it approximately starts from April and lasts to June (Chi et al. 2005; Ding 2007; Qiang and Yang 2008). As the major rainy season in South China, the FRS contributes about $40 \%-50 \%$ of the total annual precipitation. The anomalous behaviors of the FRS precipitation often cause serious hazards such as landslide and city waterlogging and thereby large economic losses (Sun and Zhao 2000; Wang et al. 2011).

From a long-term mean point of view, the nature of precipitation is different during the early and late stages of the FRS because the burst/onset of the South China Sea summer monsoon (SCSSM) occurs within the FRS (Yuan et al. 2010). As a result, the early stage of the FRS (i.e., before the onset of the SCSSM) is mainly featured with frontal precipitation (Chi et al. 2005; Yuan et al. 2010). The water vapor is mainly transported to South China via the westerly winds across the Arabian Sea and the southeasterly winds along the southwestern edge of the western Pacific subtropical high (Chi et al. 2005; Chang et al. 2006). In contrast, the late stage of the FRS (i.e., after the onset of SCSSM) is mainly featured with monsoonal precipitation (Chi et al. 2005; Yuan et al. 2010). The water vapor is mainly from the cross-equatorial flow over the Bay of Bengal and South China Sea (Chi et al. 2005; Chang et al. 2006).

Previous studies have investigated the atmospheric circulations and water vapor transport that account for the interannual variations of the FRS precipitation. It reveals that above-normal FRS precipitation is often associated with enhanced and southwestward-extended western Pacific subtropical high, southward-shifted upper-tropospheric subtropical East Asian jet stream, and weakened local meridional circulation over the western Pacific (e.g., Zhang et al. 2009; Qiang and Yang 2013). The opposite holds when the FRS precipitation is below normal. It is also suggested that the above-normal FRS precipitation is observed when water vapor transportation from the tropical areas is abundant and the cold air from mid- and high latitudes invades southward in the meantime (Chen et al. 1991; Yuan et al. 2012). This configuration is particularly important in the early stage of the FRS (Wu et al. 2006; Yuan et al. 2010, 2012).

The interannual variations of the FRS precipitation could be linked to atmospheric external forcing such as sea surface temperature (SST) anomalies. Although El Niño-Southern Oscillation (ENSO) is an important driver of the EASM rainfall (e.g., Huang and Wu 1989; Zhang et al. 1999; Zhang and Sumi 2002; Wu et al. 2003; Ding and Chan 2005; Huang et al. 2012; Wang and Gu 2016), it is only marginally related to the FRS precipitation (Chan and Zhou 2005; Qiang and Yang 2013; Yao et al. 2016). In contrast, the SST anomalies over the western Pacific warm pool could alter the local meridional circulation and thereby influence the FRS precipitation (Cai et al. 2002; Deng and Wang 2002; Qiang and Yang 2013).

It is noteworthy that almost all the above-mentioned studies about the FRS precipitation are based on monthly mean data. The average over April-June or May-June is usually chosen to represent the FRS season. However, the start and end dates of the FRS vary substantially from year to year (Qiang and Yang 2008; also see Fig. 2a herein). Therefore, it may not be sufficient to use the monthly mean data to investigate the variations of the FRS precipitation and the associated mechanism. In this paper, we employ the definition of the FRS based on daily mean data and revisit the interannual variations of the FRS precipitation accordingly. The associated atmospheric processes and possible influences from the tropical Pacific are also discussed.

Section 2 describes the data and methodology used in this study. Section 3 shows the FRS precipitation over South China and its interannual variability based on daily mean data. Sections 4 and 5 explore the processes that lead to interannual variations of the FRS precipitation from the perspective of atmospheric circulations and SST, respectively. Section 6 briefly discusses the decadal weakening in the interannual variability of the FRS precipitation. Finally, section 7 summarizes the main findings of this study, and section 8 provides further discussion.

\section{Data and methods}

Precipitation data used in this study are from the daily mean rainfall dataset of 2479 Chinese stations for the period 1981-2015, archived and updated by the National Meteorological Information Center, China Meteorological Administration (CMA). Atmospheric data are from the National Centers for Environmental Prediction (NCEP)-National Center for Atmospheric Research (NCAR) daily mean reanalysis dataset, spanning the period 1948 to date (Kalnay et al. 1996). This dataset has a $2.5^{\circ}$ by $2.5^{\circ}$ horizontal resolution and extends from 1000 to $10 \mathrm{hPa}$ with 17 vertical pressure levels. SST data are from the monthly mean Hadley Centre Sea Ice and Sea Surface Temperature dataset (HadISST), which is a unique combination of monthly globally complete fields of SST and sea ice concentrations on a $1^{\circ}$ by $1^{\circ}$ grid from 1870 to the present (Rayner et al. 2003).

Following the definition of the National Climate Center of CMA, "southern China" as used herein is defined as four provinces in South China including Fujian, Guangdong, Guangxi, and Hainan Provinces (National Climate Center 2013). Among the 2479 stations, 261 stations are 


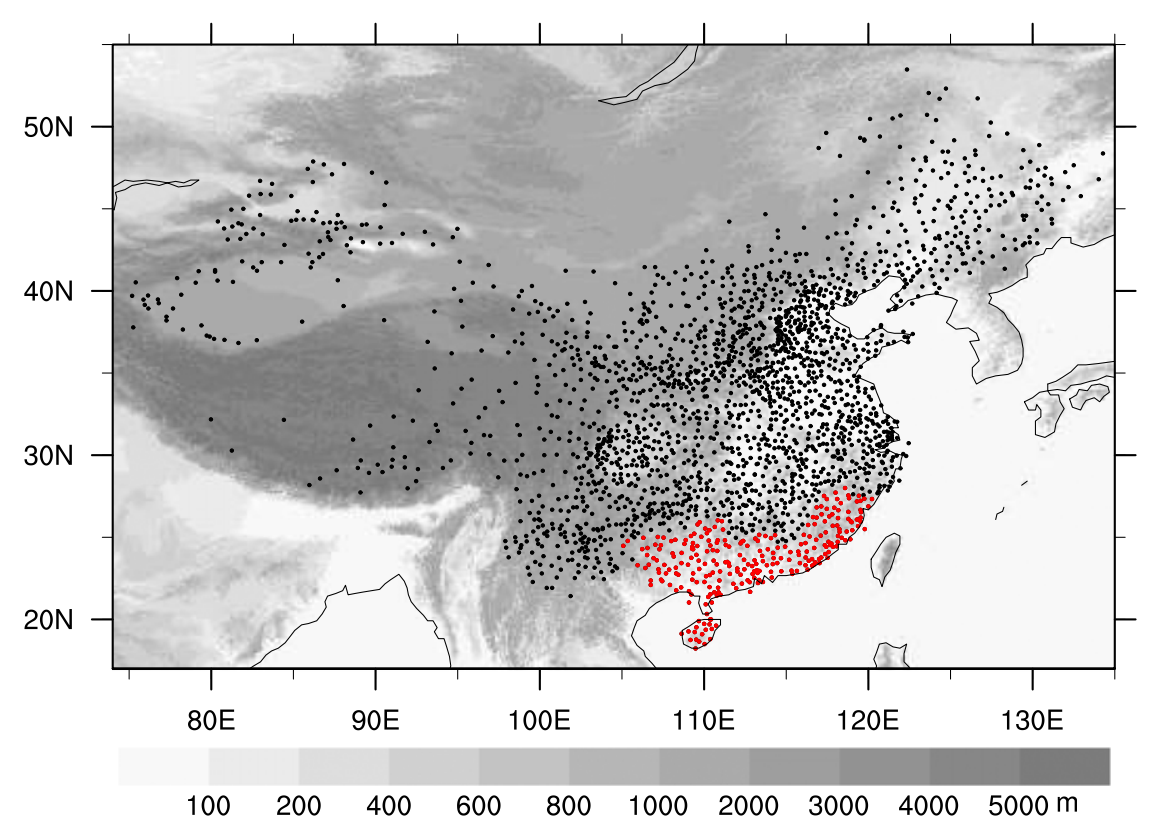

FIG. 1. Locations of the 2479 meteorological stations. Red dots indicate the 261 stations in Fujian, Guangdong, Guangxi, and Hainan Provinces that are used to define the FRS over South China.

located in South China (red dots in Fig. 1), which consist of $66,86,90$, and 19 stations in Fujian, Guangdong, Guangxi, and Hainan Provinces, respectively. The start date of the FRS is defined according to the following criteria (National Climate Center 2013):

1) The start date of the FRS in Guangdong (Guangxi) Province is defined as the first day when the daily precipitation that exceeds $38 \mathrm{~mm}$ is observed at no less than $50 \%$ of all the stations [i.e., 43 (45) stations] after 1 March and the daily precipitation that exceeds $38 \mathrm{~mm}$ is observed at no less than $10 \%$ of all the stations [i.e., 9 (9) stations] on the previous day.

2) The start date of the FRS in Fujian (Hainan) Province is defined as the first day when the daily precipitation that exceeds $38 \mathrm{~mm}$ is observed at no less than $50 \%$ of all the stations [i.e., 33 (10) stations] after 1 April and the daily precipitation that exceeds $38 \mathrm{~mm}$ is observed at no less than $10 \%$ of all the stations [i.e., 7 (2) stations] on the previous day.

3) The start date of the FRS over South China is defined as the earliest date among the above four start dates of the FRS.

The end date of the FRS is defined according to the following criteria (National Climate Center 2013):

1) Daily precipitation averaged over the 261 stations is below $7 \mathrm{~mm}$ for five successive days after 1 June.
2) Daily precipitation that exceeds $38 \mathrm{~mm}$ is observed at less than $5 \%$ of the 261 stations (i.e., 13 stations) for five successive days.

3) The ridge line of the western Pacific subtropical high is located north of $22^{\circ} \mathrm{N}$ for five successive days.

4) The end date of the FRS is defined as the first date that daily precipitation averaged over the 261 stations is below $7 \mathrm{~mm}$ when the above three criteria are met.

Based on these definitions, the start and end dates of the FRS are monitored and archived in the National Climate Center of CMA. It is noteworthy that rainfall area is natural and should not be limited by government areas. If we look at Fig. 1 carefully, however, it is clear that there is a quasi-zonally oriented high topography in South China, comprising the Nanling Mountains and Wuyi Mountains (see Fig. 1 of Chen et al. 2009). These mountains are important to steer the rain belt and to form the FRS over South China. Given that almost all the 261 stations in the four provinces are located at and to the south of this high topography, it is reasonable to use these stations to define the FRS over South China.

Figure 2a shows the time series of the start and end dates of the FRS during the period 1981-2015, both of which exhibit obvious interannual variations. The averaged start and end date is 6 April and 4 July, respectively. The length of the FRS also varies year by 
(a) Start \& end date of FRS

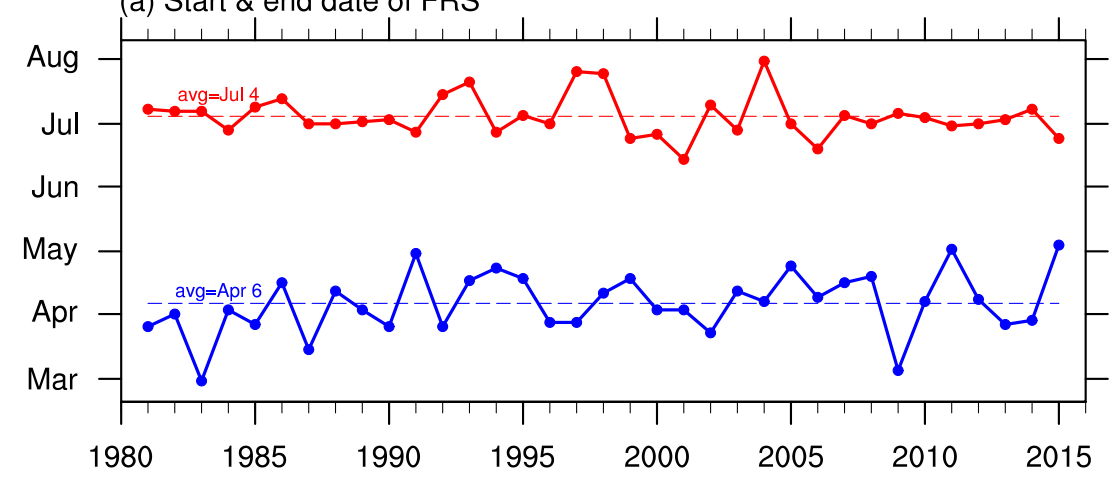

(b) Length of FRS

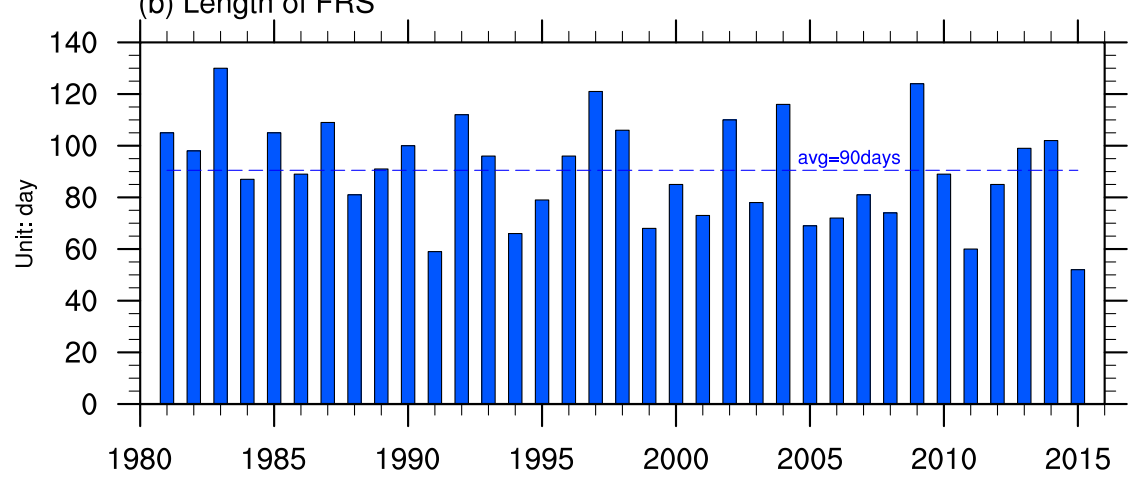

FIG. 2. (a) The start (blue solid line) and end (red solid line) dates of the FRS over South China and their long-term means (dashed lines) during the period 1981-2015. (b) The length of the FRS over South China during the period 1981-2015.

year, and the averaged length is 90 days (Fig. 2b). In this study, the FRS period denotes the period between the start and end date of the FRS, and its length varies year to year. Accordingly, the FRS precipitation of each year is defined as the total precipitation amount during the FRS period, and the atmospheric variables during the FRS period of each year are extracted for the subsequent analyses. The period 1981-2015, which is the common period among different datasets, is analyzed in this study. The confidence level of composite and regression analysis is evaluated through the two-tailed Student's $t$ test.

\section{The FRS precipitation and its interannual variation}

Figure $3 \mathrm{a}$ shows the long-term mean precipitation during the FRS. Almost all the stations in South China observe an accumulated precipitation that exceeds $600 \mathrm{~mm}$. Two maximum precipitation centers are located over northwestern Fujian Province (near $27.5^{\circ} \mathrm{N}, 117.5^{\circ} \mathrm{E}$ ) and central Guangdong Province (near $22.5^{\circ} \mathrm{N}, 112.5^{\circ} \mathrm{E}$ ), respectively, and the maximum precipitation exceeds $900 \mathrm{~mm}$. The average length of the FRS is only $25 \%$ of a year (90 days), but the precipitation in the FRS generally accounts for more than $40 \%$ of the annual total precipitation over South China (Fig. 3b). This result suggests that the FRS precipitation is quite important for the hydrological cycle over South China.

Figure 4 shows the normalized 261-station-averaged FRS precipitation over South China, referred to as the FRS precipitation index hereafter, for the period 1981-2015, where a positive (negative) index means sufficient (deficient) FRS precipitation. The index features strong interannual variability and a linear trend of -0.14 decade $^{-1}$, which is below the $95 \%$ confidence level. In the following section, a composite analysis is performed to reveal the anomalies associated with this index. The 0.5 standard deviation is used to select typical FRS precipitation cases. Based on this criterion, nine years are identified as years with sufficient FRS precipitation (1981, 1983, 1986, 1987, 1992, 1993, 1997, 1998, and 2014), and nine years are identified as years with deficient FRS precipitation (1985, 1988, 1991, 1994, 1995, 1999, 2003, 2011, and 2015). Hereafter, they are referred to as wet and dry FRS years, respectively. 
(a) Climatology of FRS precipitation

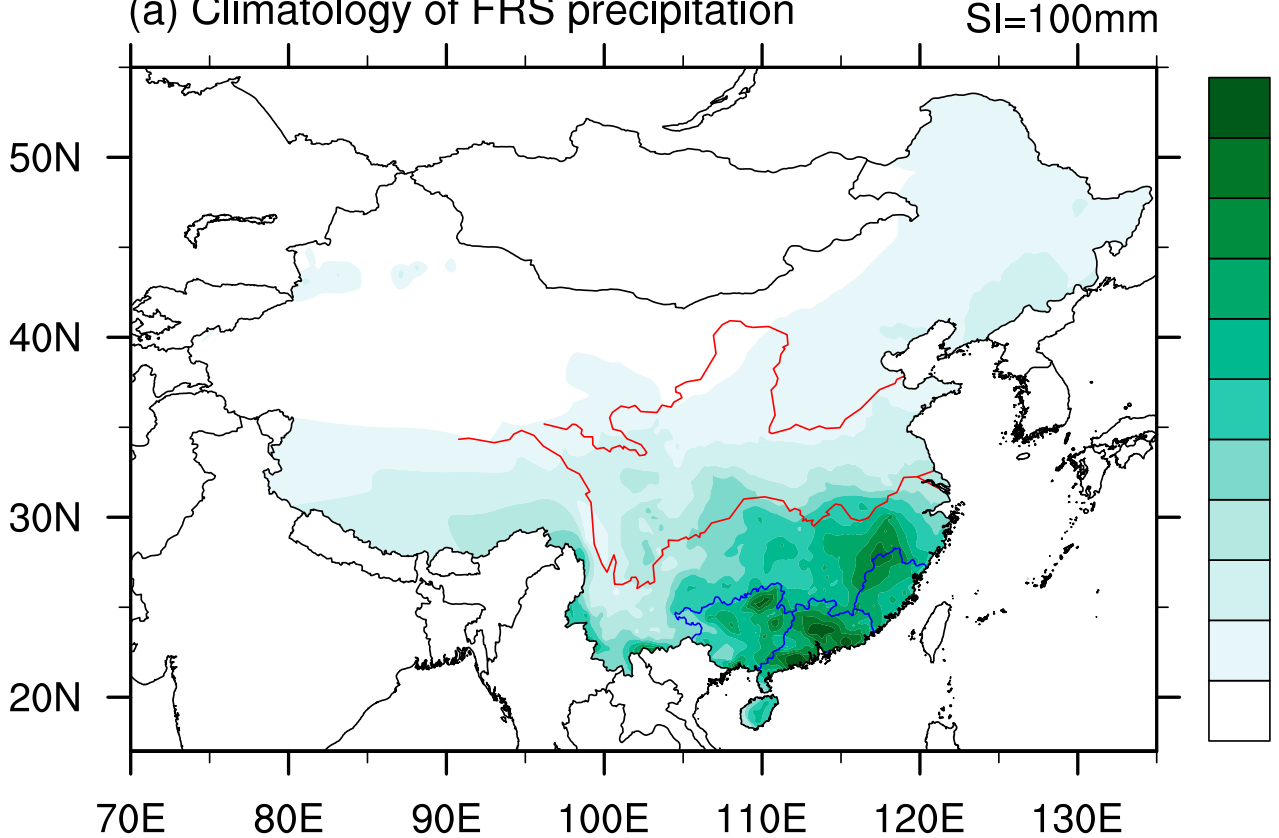

1000

900

800

700

600

500

400

300

200

100

(b) Percentage w.r.t annual total

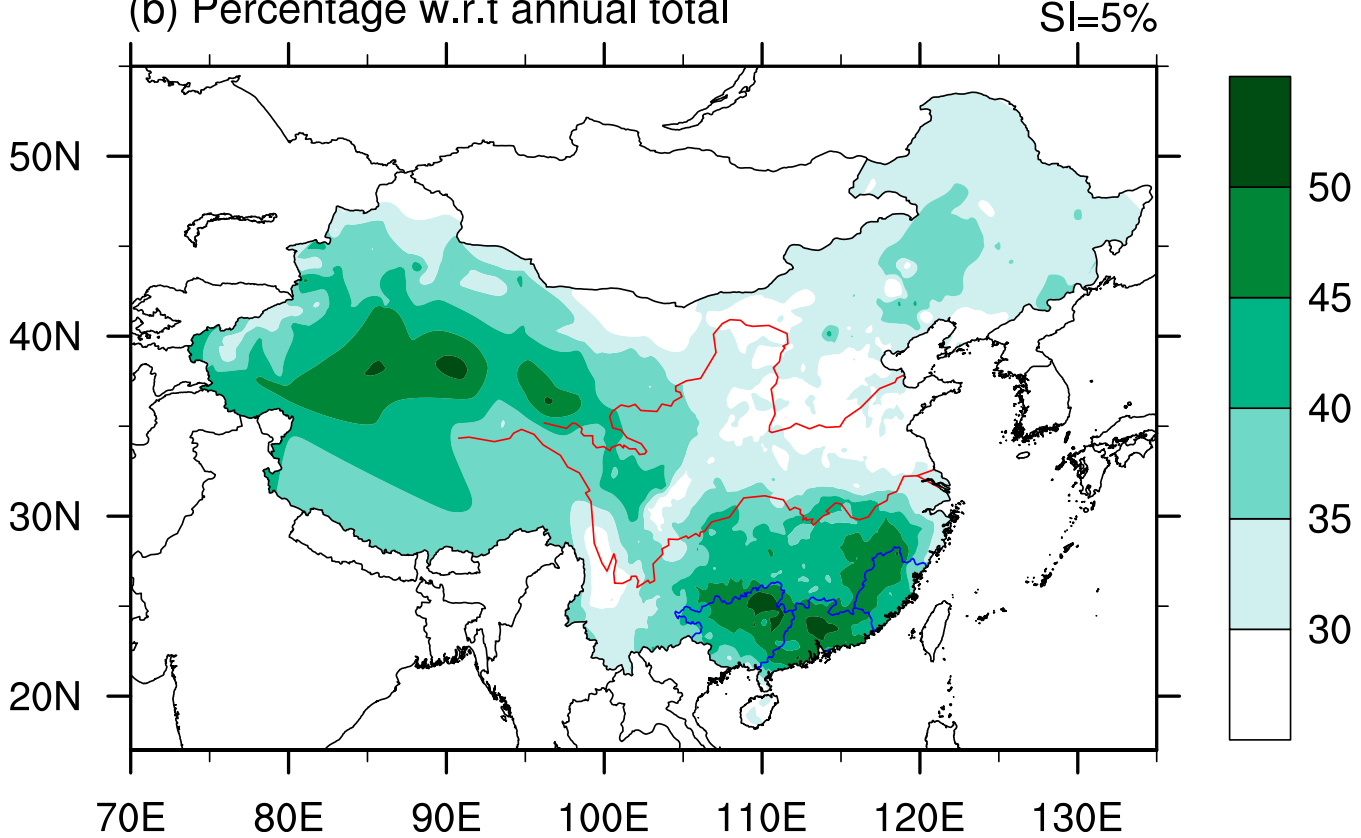

FIG. 3. (a) The climatology of accumulated precipitation during the FRS. (b) The ratio of the FRS precipitation with respect to the annual totals. Shading interval is $100 \mathrm{~mm}$ in (a) and 5\% in (b). Red lines indicate the Yellow River and Yangtze River. Blue lines indicate the boundaries of Fujian, Guangdong, and Guangxi Provinces.

Figure 5 shows the composite precipitation in wet and dry FRS years and their differences. In wet FRS years, the accumulated precipitation generally exceeds $800 \mathrm{~mm}$ over all of South China, and the maximum exceeding $1600 \mathrm{~mm}$ is observed in southwestern Guangdong Province (near $22^{\circ} \mathrm{N}, 112.5^{\circ} \mathrm{E}$ ) (Fig. 5a). In dry FRS years, in contrast, the accumulated precipitation is generally on the order of $500-600 \mathrm{~mm}$ over most of South China, and the maximum is just above $800 \mathrm{~mm}$ (Fig. 5b). The differences between the two cases are quite distinct. More precipitation is observed over all of South China in wet FRS years than in dry FRS years, and the precipitation center differences exceed $600 \mathrm{~mm}$ in Guangdong Province (Fig. 5c). 


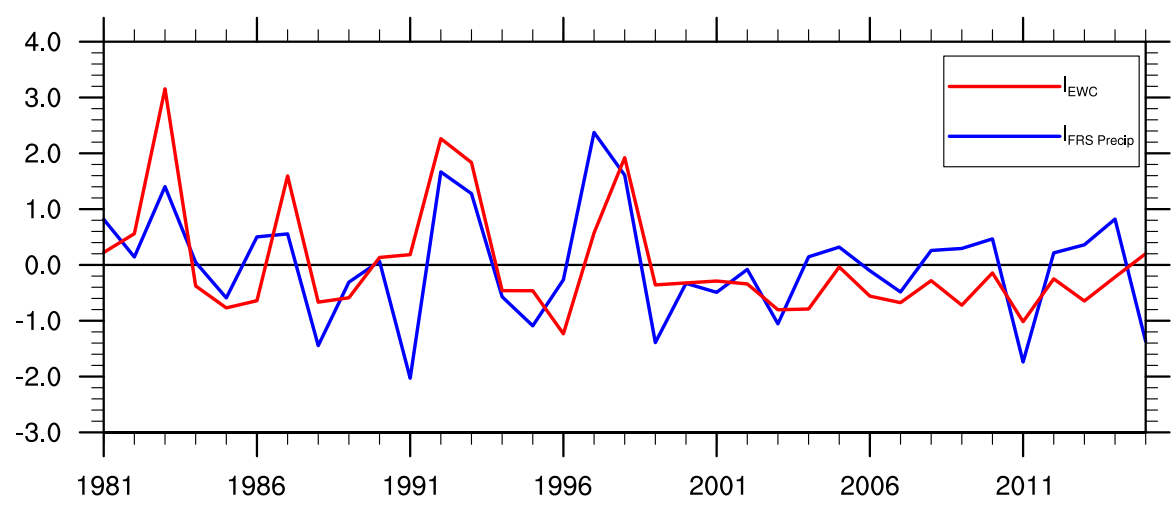

FIG. 4. The normalized FRS precipitation index (blue) and $I_{\mathrm{EWC}}$ (red) for the period 1981-2015.

\section{Associated atmospheric circulations}

The climatology of 200-hPa wind field during the FRS features a westerly jet stream along $35^{\circ}-40^{\circ} \mathrm{N}$ and prevailing easterly winds to the south of approximately $15^{\circ} \mathrm{N}$ (Fig. 6a). An anticyclone is formed in between with its center being situated over the Indochina Peninsula. Compared with those in dry FRS years, both the westerly jet stream and the tropical prevailing easterly winds are weakened significantly in wet FRS years (Fig. 6b). An anomalous cyclone is observed above the eastern Tibetan Plateau (at approximately $30^{\circ} \mathrm{N}, 95^{\circ} \mathrm{E}$ ), implying that the climatological anticyclone over the Indochina Peninsula (Fig. 6a) is weakened and southward shifted. The center of the anticyclone over the Indochina Peninsula is located above $18^{\circ} \mathrm{N}, 102^{\circ} \mathrm{E}$ in the climatological mean sense, and it shifts to $16^{\circ} \mathrm{N}, 103^{\circ} \mathrm{E}$ in wet FRS years and to $19^{\circ} \mathrm{N}, 9^{\circ} \mathrm{E}$ in dry FRS years (not shown). This feature can also be seen from the movement of the western Pacific subtropical high. The western edge of the western Pacific subtropical high is located around $15^{\circ} \mathrm{N}$, $116^{\circ} \mathrm{E}$ in the climatological mean sense, and it shifts to approximately $14^{\circ} \mathrm{N}, 112^{\circ} \mathrm{E}$ in wet FRS years and to approximately $15^{\circ} \mathrm{N}, 119^{\circ} \mathrm{E}$ in dry FRS years (Fig. 6c). These features are generally consistent with previous studies (e.g., Qiang and Yang 2013), although details differ slightly.

The southwestward-situated western Pacific subtropical high corresponds to $850-\mathrm{hPa}$ southwesterly wind anomalies over South China and the northeastern portion of Indochina Peninsula (Fig. 6e), which enhances the climatological mean southwesterly winds in this region (Fig. 6d). This configuration could alter the FRS precipitation in two ways. First, the water vapor over South China is mainly transported via the Indochina Peninsula and the western North Pacific during the FRS in the climatological mean sense
(Fig. 7a). The southwesterly wind anomalies can enhance the water vapor transport from the Indochina Peninsula significantly (Fig. 7b), providing a favorable moisture environment over South China for abundant FRS precipitation. Second, the background $850-\mathrm{hPa}$ air temperature is warmer over the Indochina Peninsula than over South China (Fig. 6e). Hence, the southwesterly wind anomalies will advect warm air toward South China. Although the enhanced moisture transportation and warm advection toward South China can be observed throughout the troposphere, they are stronger in the lower than in the mid- and upper troposphere (not show). As a result, the convective instability $\left(-\partial \theta_{\mathrm{se}} / \partial p\right)$ in the lower troposphere is enhanced over South China (Fig. 6f), providing favorable dynamical conditions for enhanced ascending motion (Fig. 8) over South China. Therefore, the circulationinduced moisture environment and dynamical conditions both facilitate enhanced FRS precipitation over South China.

To further reveal how the anomalous ascending motion is induced, the linearized omega equation was diagnosed as follows, which is similar to previous studies (e.g., Kosaka et al. 2011; Hu et al. 2017) but additionally considers the role of the diabatic heating:

$$
\begin{aligned}
\omega^{\prime}= & \left(\nabla^{2}+\frac{f^{2}}{\sigma} \frac{\partial^{2}}{\partial p^{2}}\right)^{-1} \frac{f}{\sigma} \frac{\partial}{\partial p}\left[\overline{\mathbf{V}} \cdot \nabla \zeta^{\prime}+\mathbf{V}^{\prime} \cdot \nabla(f+\bar{\zeta})\right] \\
& +\left(\nabla^{2}+\frac{f^{2}}{\sigma} \frac{\partial^{2}}{\partial p^{2}}\right)^{-1} \frac{R}{\sigma p} \nabla^{2}\left(\overline{\mathbf{V}} \cdot \nabla T^{\prime}+\mathbf{V}^{\prime} \cdot \nabla \bar{T}\right) \\
& -\left(\nabla^{2}+\frac{f^{2}}{\sigma} \frac{\partial^{2}}{\partial p^{2}}\right)^{-1} \frac{R}{\sigma p} \nabla^{2} Q^{\prime} \\
\equiv & \omega_{\text {dyn }}^{\prime}+\omega_{\text {therm }}^{\prime}+\omega_{Q}^{\prime}
\end{aligned}
$$

where overbars indicate climatological mean quantities, and primes indicate the composite anomalies during the 
(a) Wet FRS years

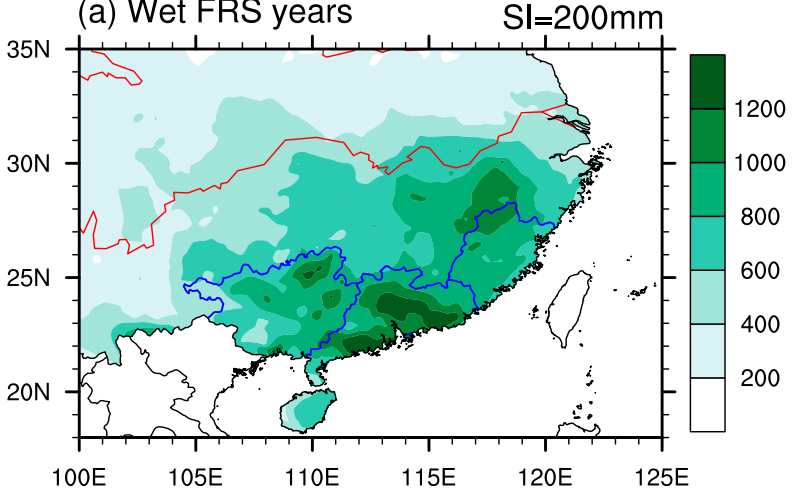

(b) Dry FRS years

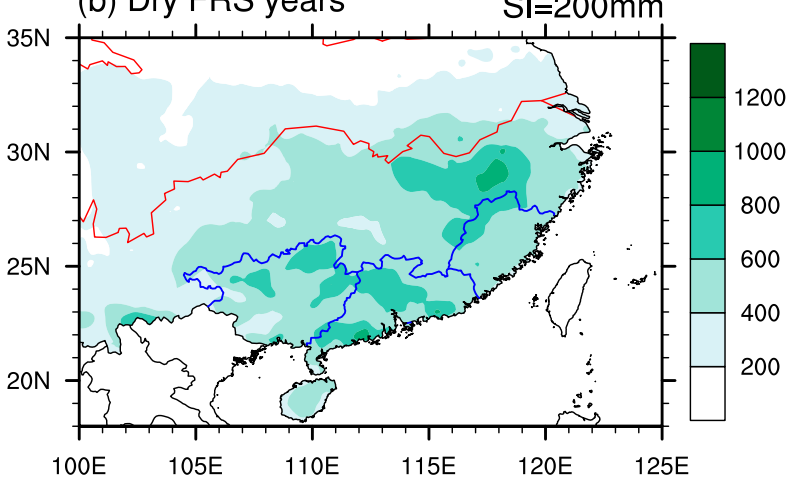

(c) (a)-(b)

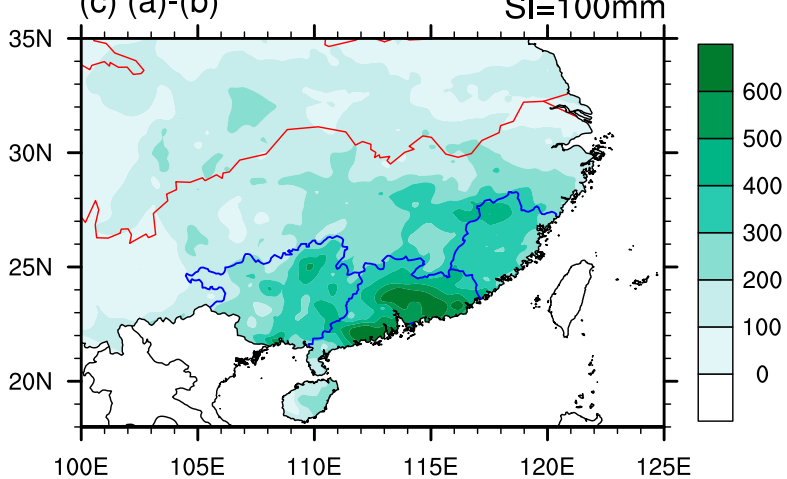

FIG. 5. Accumulated FRS precipitation during (a) wet FRS years, (b) dry FRS years, and (c) their difference. Shading intervals are $200 \mathrm{~mm}$ in (a) and (b) and $100 \mathrm{~mm}$ in (c). Red lines indicate the Yellow River and Yangtze River. Blue lines indicate the boundaries of Fujian, Guangdong, and Guangxi Provinces.

FRS. The $f$ is the Coriolis parameter, $\mathbf{V}$ is the horizontal wind vector, $\zeta$ is the vertical component of relative vorticity, $\sigma=R / p\left[\left(R T / c_{p} p\right)-(\partial T / \partial p)\right]$ is the background static stability, $R=287 \mathrm{~J} \mathrm{~kg}^{-1} \mathrm{~K}^{-1}$ is the gas constant for dry air, $c_{p}=1004 \mathrm{~J} \mathrm{~K}^{-1} \mathrm{~kg}^{-1}$ is the specific heat of dry air at constant pressure, and $Q$ is the diabatic heating rate in $\mathrm{K} \mathrm{s}^{-1}$ estimated as the residual of thermodynamic equation based on four-times-daily NCEPNCAR reanalysis data. The first, second, and third terms on the right-hand side of Eq. (1) represent the vertical velocity anomalies induced by the vertical difference of vorticity horizontal advection, the horizontal temperature advection, and the diabatic heating, marked as $\omega_{\text {dyn }}^{\prime}, \omega_{\text {therm }}^{\prime}$, and $\omega_{Q}^{\prime}$, respectively. Figure 9 shows the distribution of composited vertical motion between wet and dry FRS years $\left(\omega_{\text {obs }}^{\prime}\right), \omega_{\text {dyn }}^{\prime}, \omega_{\text {therm }}^{\prime}$, and $\omega_{Q}^{\prime}$ at $500 \mathrm{hPa}$. It reveals that $\omega_{Q}^{\prime}$ is dominating (Fig. 9d), and $\omega_{\text {dyn }}^{\prime}$ is negligible (Fig. 9b), implying the key role played by diabatic heating.

Although the magnitude of $\omega_{\text {therm }}^{\prime}$ is smaller than that of $\omega_{\mathrm{obs}}^{\prime}$, the patterns of $\omega_{\text {therm }}^{\prime}$ and $\omega_{\mathrm{obs}}^{\prime}$ are quite similar to each other especially over South China (Figs. 9a,c). It is inferred that there exists local positive feedbacks in the formation of $\omega_{\text {obs }}^{\prime}$. That is, the temperature advection discussed in the previous paragraph (Fig. 6e) can induce some initial ascending anomalies over South China whose magnitude is approximately one-third of $\omega_{\text {obs }}^{\prime}$ (Figs. 9a,c). This process enhances precipitation and thereby latent heat releases over South China. The resultant diabatic heating anomalies will further enhance ascending motion (Fig. 9d) and precipitation, forming a self-maintained positive feedback between precipitation and ascending motion. Compared with previous studies that emphasize the role of enhanced water vapor transport and the shift of the western Pacific high on the FRS precipitation (e.g., Zhang et al. 2009; Qiang and Yang 2013), our results suggest that the warm advection induced by the southwesterly wind anomalies plays a crucial role to increase convective instability and shape anomalous ascending motion over South China and thereby to influence the interannual variations of the FRS precipitation. This mechanism is similar to that observed in the interannual variability of mei-yu precipitation (Kosaka et al. 2011).

\section{Associated tropical Pacific SST}

Figure 10a shows the composite anomalies of SST between wet and dry FRS years in spring [March-May (MAM)], which leads the FRS by approximately one month. Strong negative SST anomalies are observed over the tropical and subtropical western Pacific, consistent with previous studies (e.g., Cai et al. 2002; Deng and Wang 2002; Qiang and Yang 2013). In addition, strong positive SST anomalies are observed over the tropical eastern Pacific, which was not reported by previous studies. These east-west SST anomalies form a zonal SST dipole in the tropical Pacific that resembles the mature phase of El Niño (Fig. 10a), indicating a weakened east-west SST gradient in the tropical Pacific. An inspection on the time evolution of this SST pattern reveals that the zonal SST dipole begins to emerge in February, amplifies in April and May, and persists to June (Fig. 10b). The negative SST 

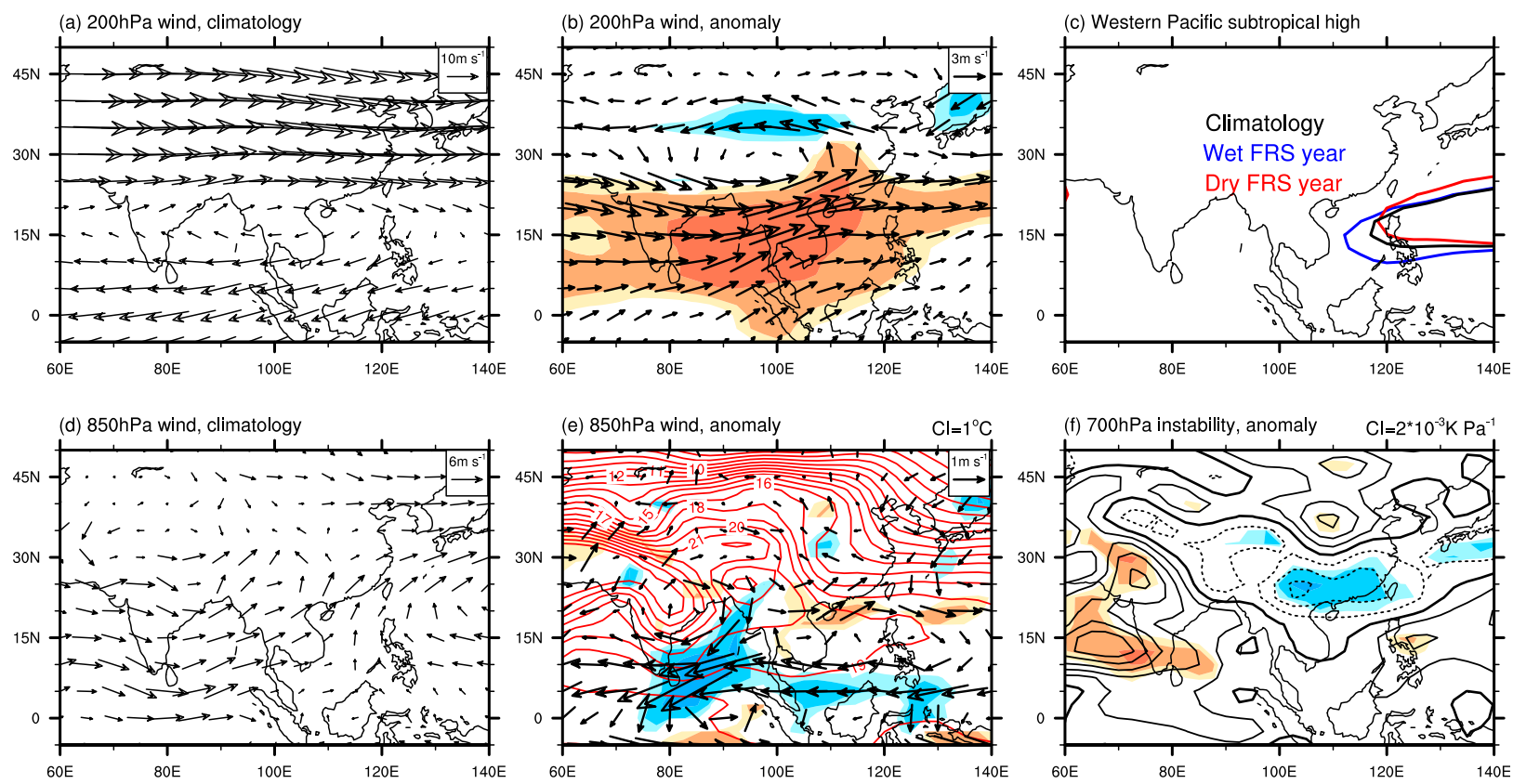

FIG. 6. (a) The climatology of 200-hPa winds during the FRS. (b) Composite anomalies of 200-hPa winds during the FRS between wet and dry FRS years. (c) The location of the western Pacific subtropical high (indicated by 5875-gpm contour) during the FRS for the climatology (black), the wet FRS years (blue), and the dry FRS years (red). (d) The climatology of 850-hPa winds during the FRS. (e) Composite anomalies of 850-hPa winds (vector) between wet and dry FRS years overlaid with the climatology of 850-hPa air temperature (contour) during the FRS. (f) Composite anomalies of $700-\mathrm{hPa}$ convective instability $-\partial \theta_{\mathrm{se}} / \partial p$ during the FRS between wet and dry FRS years. Contour intervals are $1^{\circ} \mathrm{C}$ in (e) and $2 \times 10^{-3} \mathrm{~K} \mathrm{~Pa}^{-1}$ in (f). Zero contours are bolded and contours with negative values are dashed in (f). Dark, middle, and light shading in (b), (e), and (f) indicate the $99 \%, 95 \%$, and $90 \%$ confidence levels based on two-tailed Student's $t$ test, respectively.

anomalies in the tropical western Pacific can even be tracked back to January and December, but the signals are weak and insignificant especially over the tropical eastern Pacific (Fig. 10b). This evolution process is quite different from that of El Niño (e.g., Fig. 4 of Feng et al. 2011).

Previous studies suggest that ENSO could lead to significant changes of spring (MAM) precipitation that resembles Fig. 5c over South China (e.g., Fig. 3e of Wu et al. 2003), so we examined the evolution of the Niño-3.4 index in the nine wet and nine dry FRS years. It reveals that four out of nine wet FRS years are preceded by El Niño (Fig. 11a), and three (four) out of nine dry FRS years are preceded by La Niña (El Niño) (Fig. 11b). There is large spread of the Niño-3.4 index within wet (dry) cases, but the composite mean is positive (negative) for wet (dry) cases after March (Fig. 11). These results suggest that ENSO may play some role to modulate the FRS precipitation, but its role seems to be vague. In contrast, the zonal SST dipole that is observed in spring in the tropical Pacific is likely responsible for the interannual variations of the FRS precipitation.

A similar SST dipole in the tropical Pacific was also identified in our previous study (Gu et al. 2015). It was suggested to exert significant influences on the autumn precipitation over South China. The interannual variation of the autumn precipitation over southern China can be better explained by the zonal SST dipole than by the SST anomalies over either the tropical eastern or western Pacific alone ( $\mathrm{Gu}$ et al. 2015). It motivated us to define a similar index to reflect the east-west contrast (EWC) of the tropical SST as follows:

$$
I_{\mathrm{EWC}}=\mathrm{SST}_{E}^{*}-\mathrm{SST}_{W}^{*}
$$

where $\mathrm{SST}_{E}^{*}$ and $\mathrm{SST}_{W}^{*}$ denote the normalized areaaveraged SST in the tropical eastern $\left(5^{\circ} \mathrm{S}-5^{\circ} \mathrm{N}, 150^{\circ}\right.$ $\left.90^{\circ} \mathrm{W}\right)$ and western $\left(7.5^{\circ} \mathrm{S}-7.5^{\circ} \mathrm{N}, 140^{\circ}-160^{\circ} \mathrm{E}\right)$ Pacific, respectively.

Figure 4 shows the normalized MAM mean $I_{\text {EWC }}$ for the period 1981-2015. The correlation coefficient between the $I_{\text {EWC }}$ and the FRS precipitation index is 0.59 , exceeding the $99 \%$ confidence level. Lag correlation reveals that a significant correlation coefficient between the FRS precipitation index and $I_{\text {EWC }}$ begins to exceed the $99 \%$ confidence level in February and lasts to June (blue curve in Fig. 12). The correlation with $I_{\text {EWC }}$ is the strongest in MAM $(r=0.61)$ and secondarily strongest 
(a) Climatology

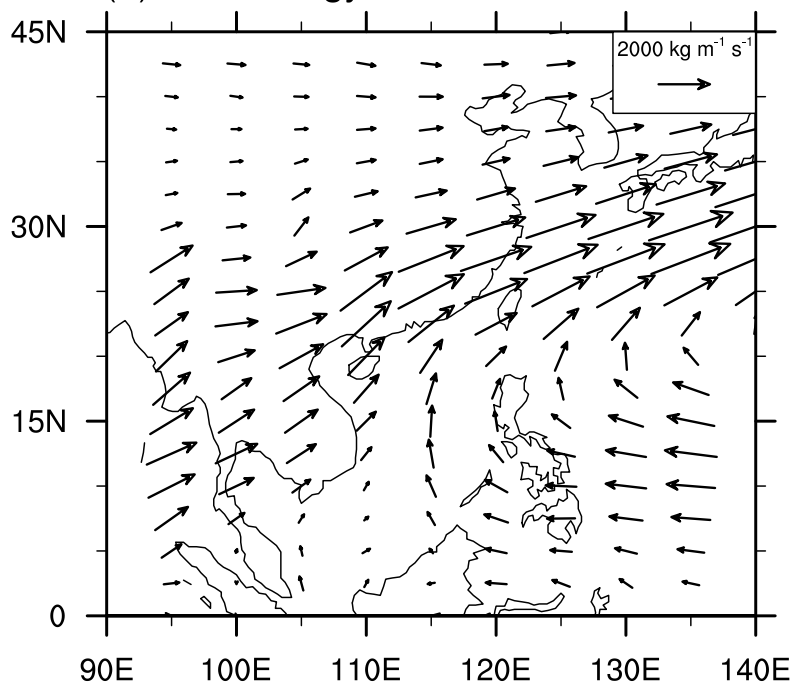

(b) wet-dry FRS

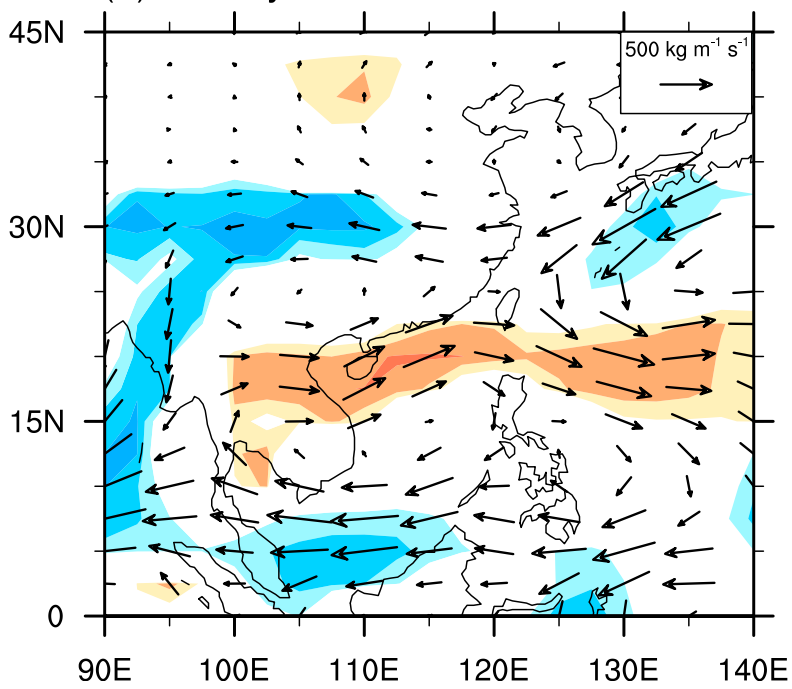

FIG. 7. (a) The climatology of column integrated water vapor flux during the FRS. (b) Composite anomalies of column-integrated water vapor flux during the FRS between wet and dry FRS years. Dark, middle, and light shading in (b) indicate the 99\%, 95\%, and $90 \%$ confidence levels based on two-tailed Student's $t$ test, respectively.

in April-June ( $r=0.58)$ (Fig. 12). These results suggest that the FRS precipitation in South China is closely linked to this zonal SST dipole over the tropical Pacific. Moreover, $I_{\text {EWC }}$ in MAM may be useful for the operational rolling prediction of the FRS precipitation in South China, whose climatological period spans from 6 April to 4 July (Fig. 2a).

The SST over the western Pacific warm pool was suggested to account for the interannual variations of the FRS precipitation (Cai et al. 2002; Deng and Wang 2002; Qiang and Yang 2013), so a comparison was made between the EWC index and the warm pool (WP) index $I_{\mathrm{WP}}$, which is defined as the averaged SST over $\left(7.5^{\circ} \mathrm{S}-7.5^{\circ} \mathrm{N}, 140^{\circ}-\right.$ $160^{\circ} \mathrm{E}$ ), the western box in the definition of $I_{\mathrm{EWC}}$. Figure 12 shows the lag correlations of the FRS precipitation index with both $I_{\mathrm{EWC}}$ and $I_{\mathrm{WP}}$. The correlation with $I_{\mathrm{EWC}}$ is always stronger than that with $I_{\mathrm{WP}}$. This is particularly clear in April, May, and June, when the climatological mean FRS is defined (Fig. 2a). The improvement in correlation coefficient (Fig. 12) is most clear in May ( 0.58 vs 0.44$)$ and June (0.46 vs 0.31 ), and it corresponds to a remarkable increase in the variance of the FRS precipitation explained by $I_{\text {EWC }}(33.6 \%$ vs $19.4 \%$ in May and $21.2 \%$ vs $9.6 \%$ in June). Hence, these results suggest that the zonal SST dipole over the tropical Pacific represented by $I_{\text {EWC }}$ plays an important role in the interannual variations of the FRS precipitation over South China.

To reveal how the zonal dipole of the tropical Pacific SST influences the FRS precipitation, atmospheric variables are regressed onto the MAM mean $I_{\text {EWC }}$. When $I_{\text {EWC }}$ is positive, the tropical eastern (western) Pacific SST is warmer (colder) than normal. This configuration of SST could lead to anomalous lower-tropospheric convergence (divergence) over the tropical eastern (western) Pacific (Fig. 13a) and weaken the climatological mean Walker circulation. As a result, the convection and diabatic heating over the tropical western Pacific is suppressed (Zhang et al. 1996; Wang et al. 2000), and the Matsuno-Gill-type anticyclonic Rossby wave responses (Gill 1980) are excited to the west of the anomalous descending center in the lower troposphere in both hemispheres (Fig. 13b). The anomalous anticyclone in the Northern Hemisphere is located near the Philippines (Fig. 13b), and it corresponds well to the southwestern shift of the western Pacific subtropical high (Fig. 6c). The corresponding southwesterly wind anomalies in the lower troposphere (not shown; pattern is almost identical to Fig. 13c) facilitate enhanced water vapor transport toward South China (Fig. 13c), providing favorable moisture conditions for abundant precipitation. Meanwhile, the enhanced lower-tropospheric southwesterly winds could advect warm air toward South China (see Fig. 6e and related discussion). It could lead to enhanced ascending motion at approximately $25^{\circ} \mathrm{N}$ (Fig. 14a), providing favorable dynamical conditions for enhanced precipitation over South China. Therefore, these results suggest that the zonal SST dipole in the tropical Pacific exerts its influences on both the moisture and the dynamical environment over South China and thereby the FRS precipitation via altering the Walker circulation and exciting a Matsuno-Gill-type Rossby wave response around the Philippines. 


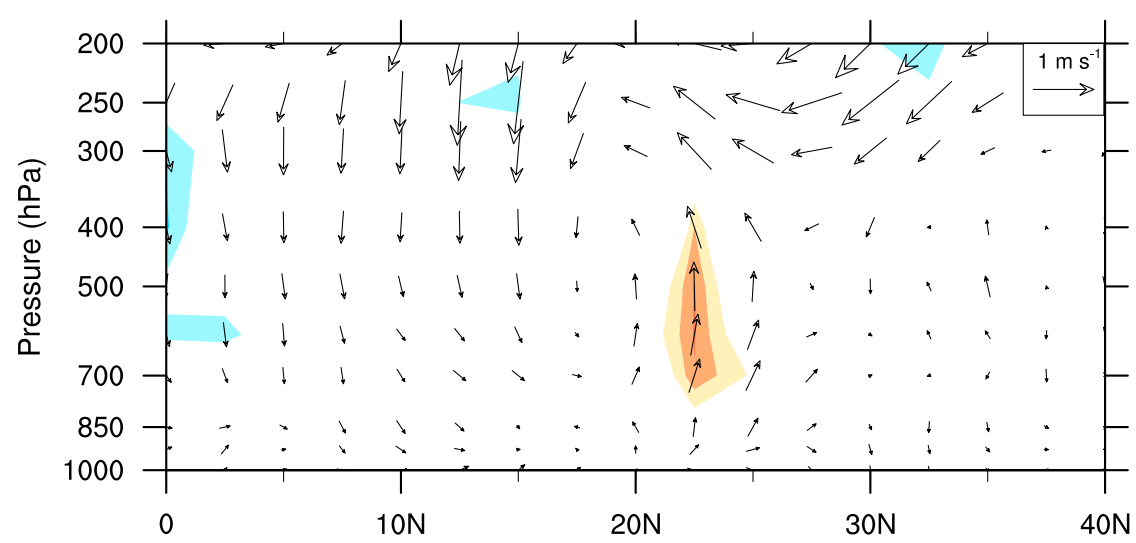

FIG. 8. Composite anomalies of meridional circulation averaged over $110^{\circ}-120^{\circ} \mathrm{E}$ during the FRS between wet and dry FRS years. Dark, middle, and light shading indicate the $99 \%$, $95 \%$, and $90 \%$ confidence levels of the vertical velocity based on two-tailed Student's $t$ test, respectively. The vertical velocity is multiplied by a factor of 500 for visual purposes.

To further verify the importance of the zonal SST dipole, anomalies of circulation and moisture flux associated with $I_{\mathrm{EWC}}$ are compared with those associated with $I_{\mathrm{WP}}$. It reveals that the cooling of SST in the tropical western
Pacific alone can also weaken the Walker circulation (Fig. 13d), but its effect is weaker than that of the SST dipole (Fig. 13a). As a result, the Rossby wave response around Philippines is insignificant although the anomalous (a) OBS

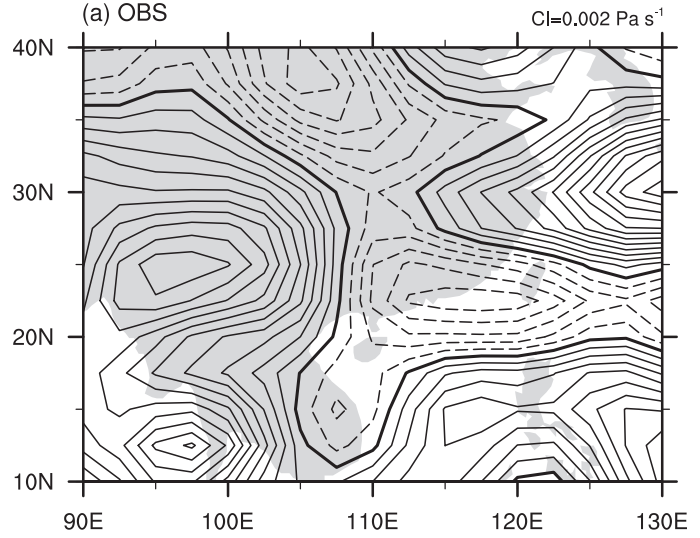

(c) THM (b) DYN

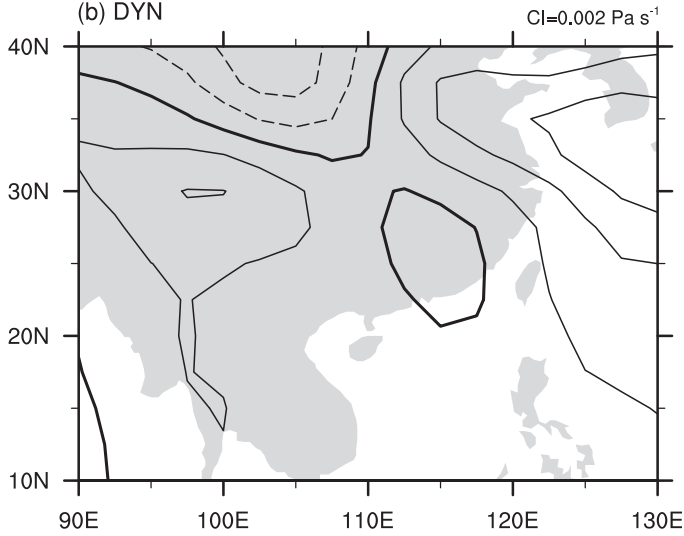

(d) $\mathrm{Q}$
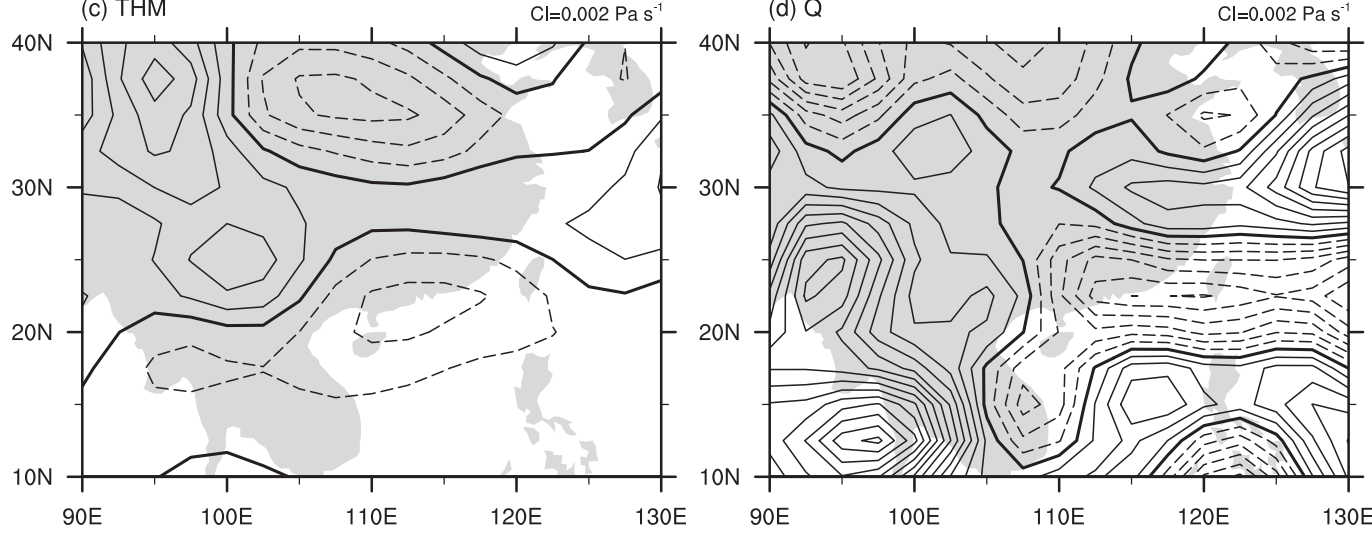

FIG. 9. (a) Composite anomalies of 500-hPa omega (i.e., $\omega_{\text {obs }}^{\prime}$ ) during the FRS between wet and dry FRS years. The 500-hPa (b) $\omega_{\text {dyn }}^{\prime}$, (c) $\omega_{\text {therm }}^{\prime}$, and (d) $\omega_{Q}^{\prime}$ obtained by solving Eq. (1) with composite circulation anomalies during the FRS between wet and dry FRS years. Contour intervals are $0.002 \mathrm{~Pa} \mathrm{~s}^{-1}$. Zero contours are bolded. 
(a) MAM

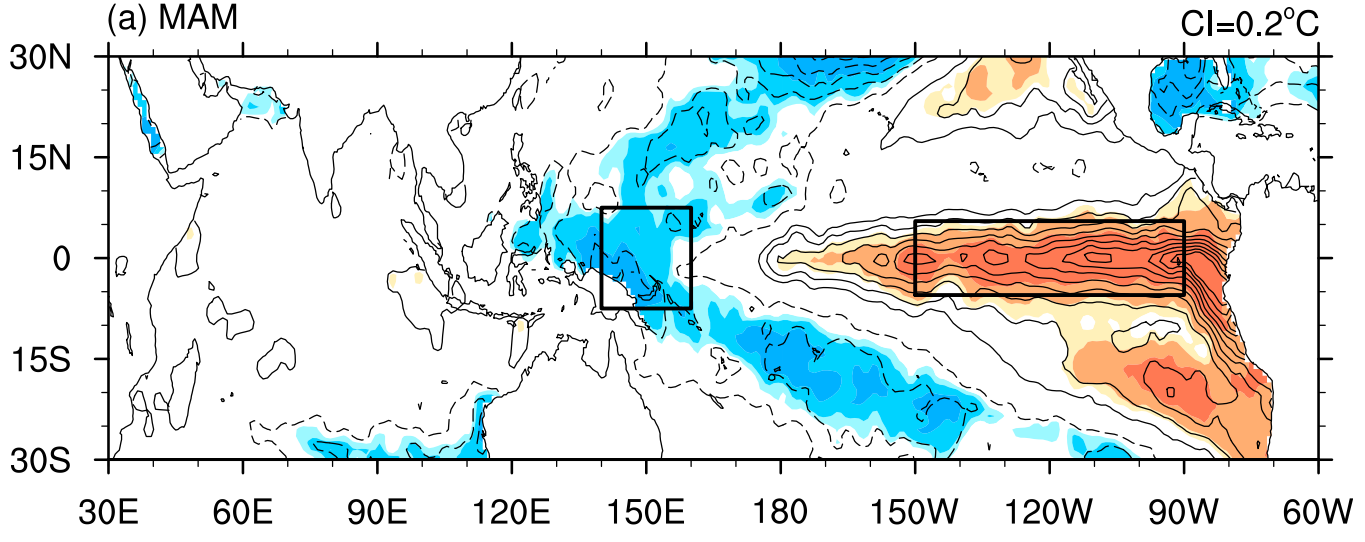

(b) $7.5^{\circ} \mathrm{S}-7.5^{\circ} \mathrm{N}$ average

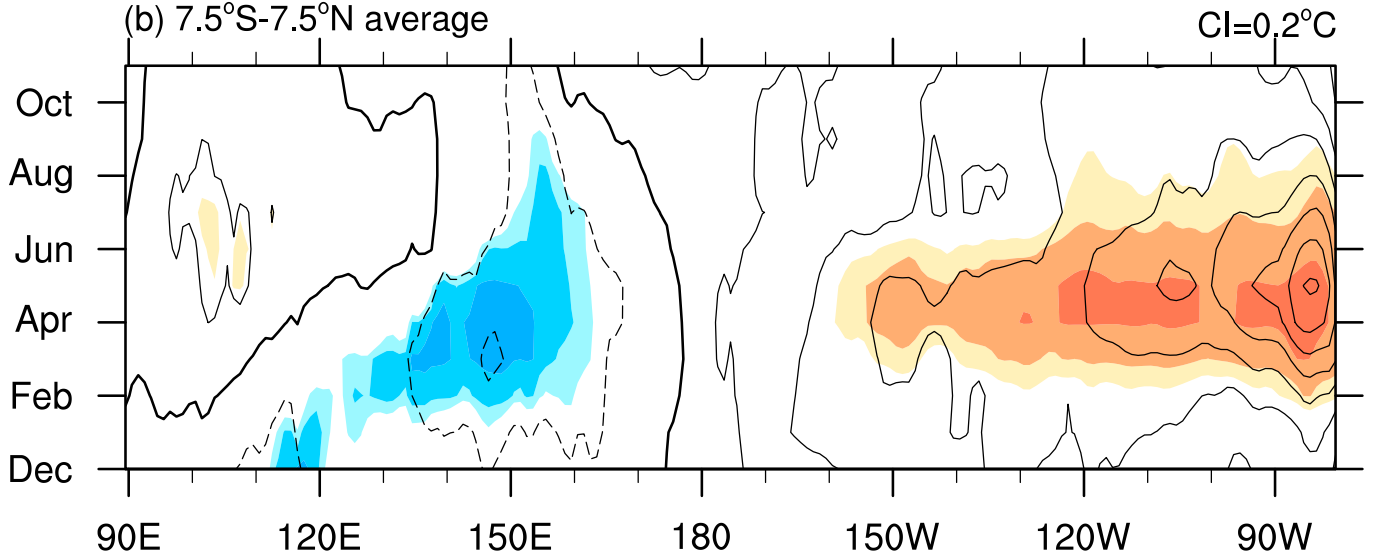

FIG. 10. (a) Composite anomalies of the MAM mean SST between wet and dry FRS years. (b) Evolution of composite anomalies of the monthly tropical SST averaged over $7.5^{\circ} \mathrm{S}-7.5^{\circ} \mathrm{N}$. Contour intervals are $0.2^{\circ} \mathrm{C}$. Zero contours are omitted in (a) and bolded in (b). Contours with negative values are dashed. Dark, middle, and light shading indicate the $99 \%, 95 \%$, and $90 \%$ confidence levels based on two-tailed Student's $t$ test, respectively. The two rectangles in (a) denote the regions used in Eq. (2) to define $I_{\text {EWC. }}$.

lower-tropospheric anticyclone is still there (Fig. 13e). The enhanced water vapor transport toward South China can also be observed (Fig. 13f), and it is weaker and less significant than those when the SST dipole is present (Fig. 13c). Moreover, the SST over the tropical western Pacific alone cannot lead to intensified ascending motion north of $20^{\circ} \mathrm{N}$ where South China is located (Fig. 14b). These contrasting results suggest that compared with the tropical western Pacific SST emphasized in previous studies, the zonal SST dipole in the tropical Pacific can better account for the variations of the FRS precipitation over South China.

\section{Weakened interannual variability of the FRS precipitation after 2000}

Previous sections have identified the interannual variations of the FRS precipitation over South China and the involved mechanism based on data spanning from 1981 to
2015. A closer inspection indicates that the interannual variability of the FRS precipitation index seems to be weakened in the latter part of the period (Fig. 4), which is confirmed by the running standard deviation with a 9-yr window (Fig. 15a). The standard deviation of the FRS precipitation index is generally above $150 \mathrm{~mm}$ before 2000 and below $120 \mathrm{~mm}$ after that (Fig. 15a). Accordingly, the whole period is divided into two from 2000. The standard deviation of the FRS precipitation index is $174 \mathrm{~mm}$ during the period $1981-99$, and it is $74 \%$ more than that $(100 \mathrm{~mm})$ during the period $2000-15$. According to the $F$ test that evaluates the difference of variance between two time series (Hayashi 1982), the difference of the FRS precipitation's variance between the two periods is significant at the $95 \%$ confidence level. An inspection on the spatial pattern suggests that the weakened variance is observed over almost all of South China (Fig. 15b). These results confirm that the variability of the FRS precipitation is weakened significantly after 2000. 

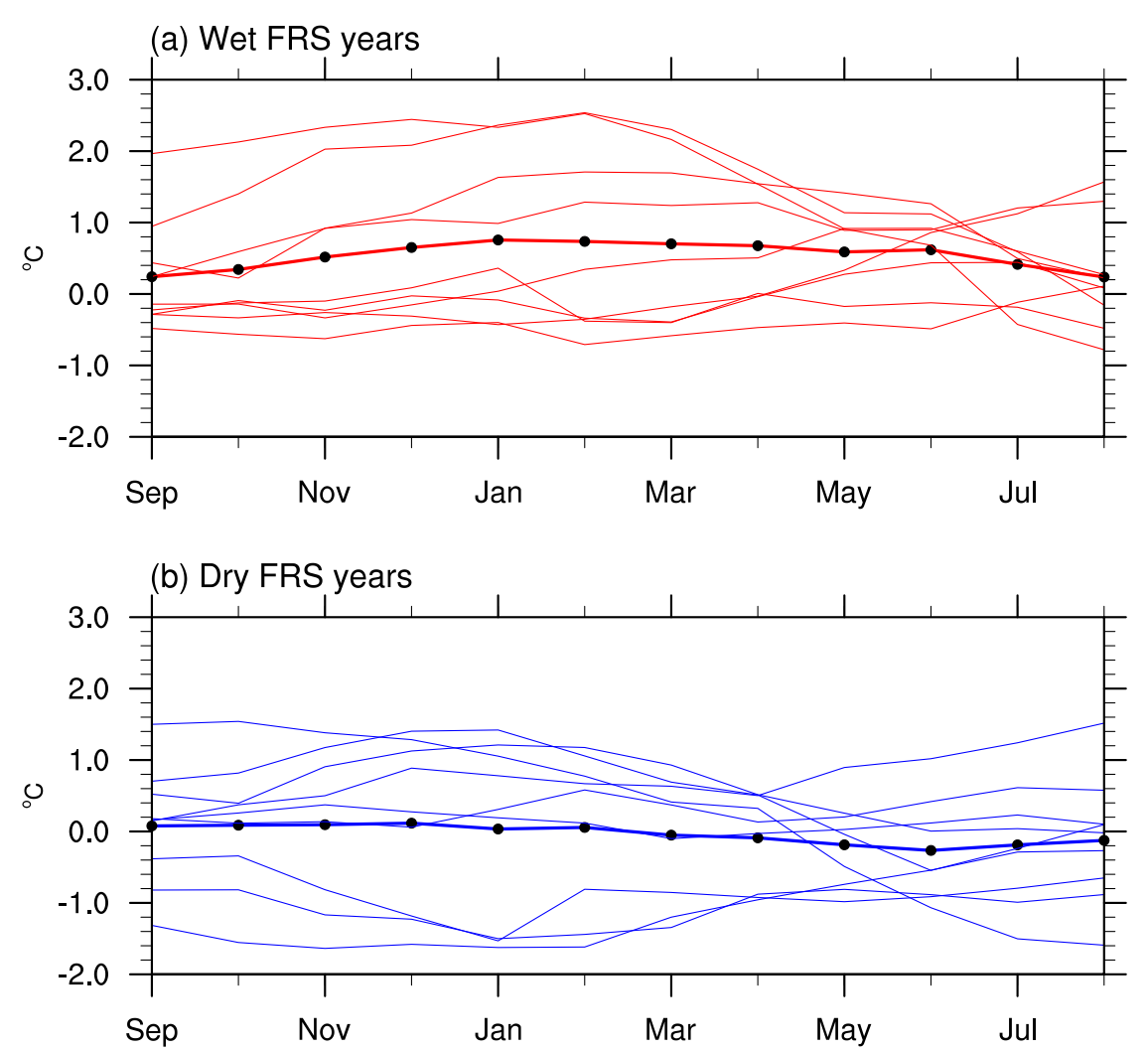

FIG. 11. (a) Evolution of the Niño-3.4 index during the nine wet FRS years (thin lines) and their composite mean (thick line with dots). (b) As in (a), but for the nine dry FRS years.

The weakened variability of the FRS precipitation is likely tied to the weakened variability of the zonal SST dipole in the tropical Pacific because the variance of $I_{\text {EWC }}$ also shows clear weakening after 2000 (Figs. 4 and 15a). This can be further confirmed by the spatial pattern (Fig. 16a) and time evolution (Fig. 16b) of the difference of SST's variance between the periods 200015 and 1981-99. The SST shows clear weakening of variance in the key regions that are closely related to the interannual variations of the FRS precipitation (i.e., the tropical eastern and western Pacific) (Fig. 16a). The weakened variance of SST is consistent with $\mathrm{Hu}$ et al. (2013) and Kumar and $\mathrm{Hu}$ (2014), who reported a weakened interannual variability of air-sea coupling in the tropical Pacific since 2000 compared with that in 1979-99. Hu et al. (2013) proposed that such suppression

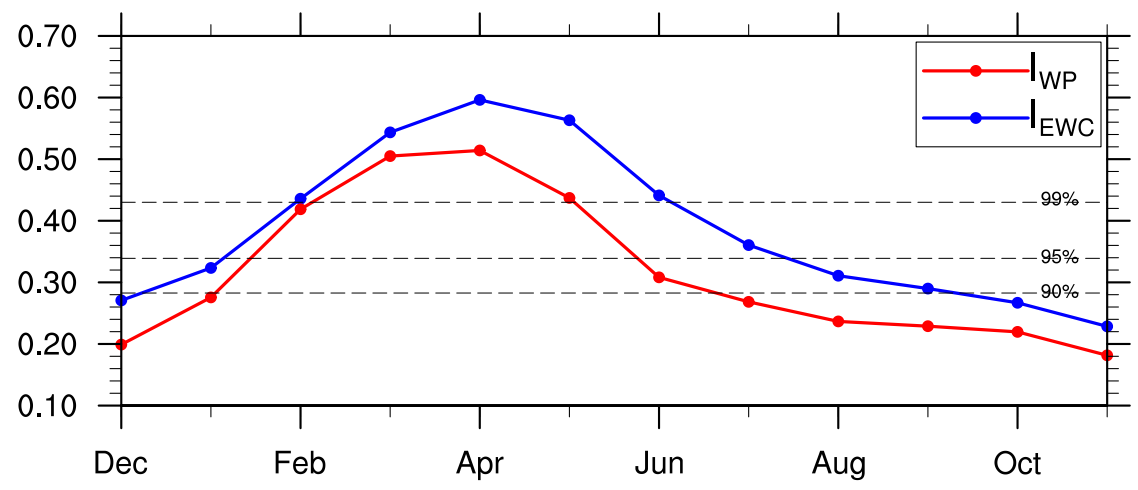

FIG. 12. Lag correlations between the FRS precipitation index and $I_{\mathrm{EWC}}$ (blue) and between the FRS precipitation index and negative $I_{\mathrm{WP}}$ (red) for the period 1981-2015. All the indices are smoothed by 3-month running mean. Dashed lines indicate the $99 \%, 95 \%$, and $90 \%$ confidence levels based on two-tailed Student's $t$ test. 
Regressed on $I_{E W C}$

(a) $850 \mathrm{hPa}$ velocity potential

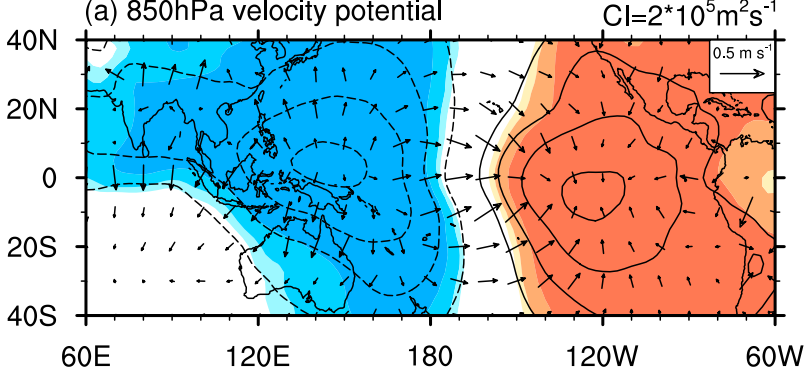

Regressed on - $I_{W P}$

(d) $850 \mathrm{hPa}$ velocity potential

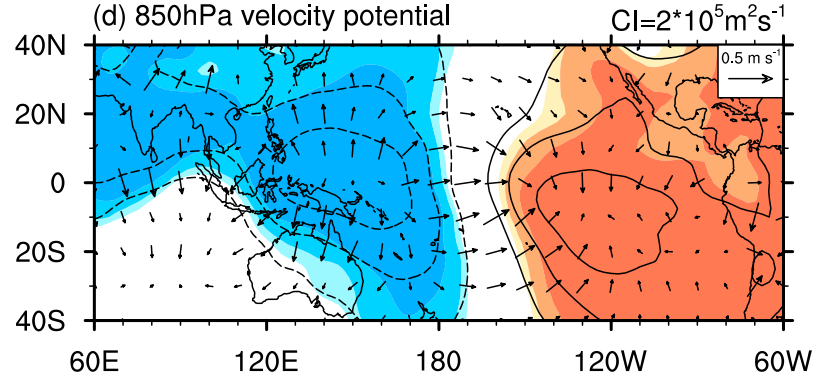

(b) $850 \mathrm{hPa}$ streamfunction

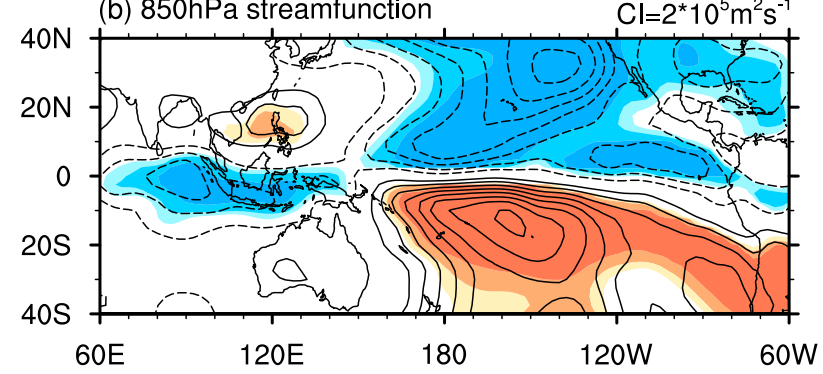

(e) $850 \mathrm{hPa}$ streamfunction

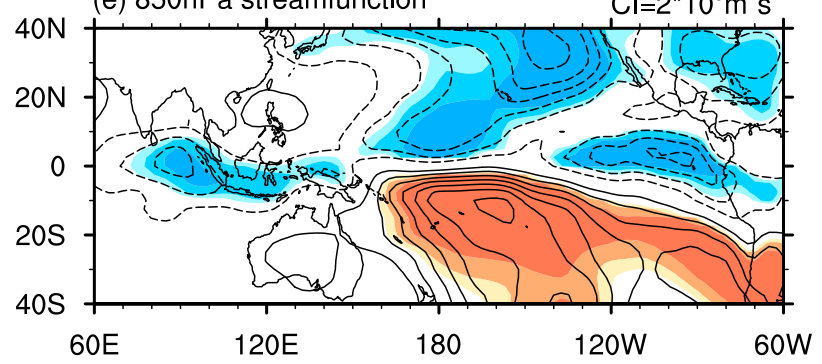

(c) moisture flux
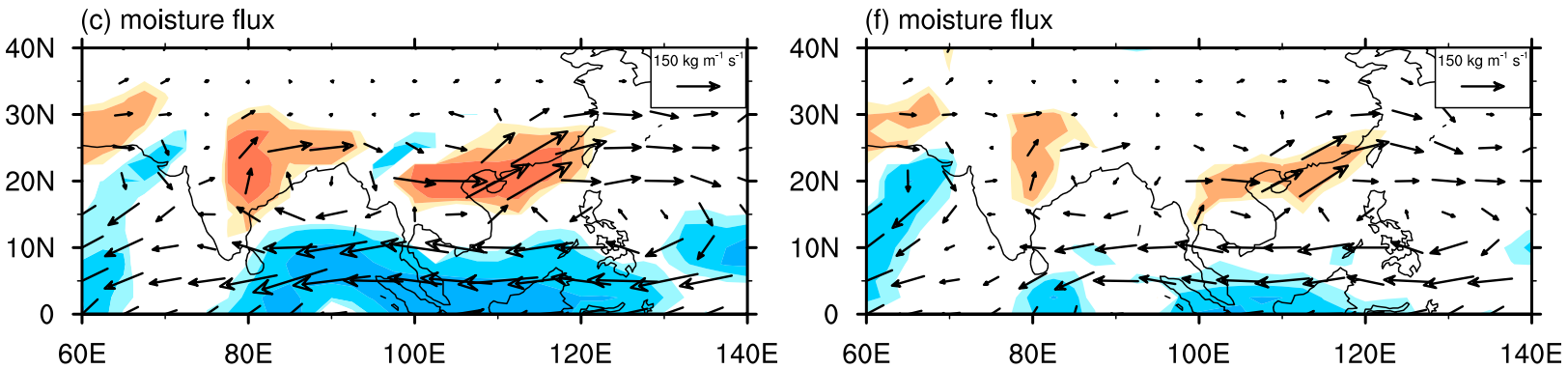

FIG. 13. Regression of (a) 850-hPa velocity potential (contour) and divergent wind (vector), (b) 850-hPa streamfunction, and (c) column-integrated water vapor flux during the FRS onto the normalized MAM mean $I_{\text {EwC }}$ for the period 1981-2015. (d)-(f) As in (a)(c), but for the normalized MAM mean negative $I_{\mathrm{WP}}$. In (a), (b), (d), and (e), contour intervals are $2 \times 10^{5} \mathrm{~m}^{2} \mathrm{~s}^{-1}$, zero contours are omitted, and contours with negative values are dashed. Dark, middle, and light shading indicate the $99 \%, 95 \%$, and $90 \%$ confidence levels based on two-tailed Student's $t$ test, respectively.

of variance since 2000 may be associated with increase of the east-west contrast of the mean state in the tropical Pacific Ocean. We could also speculate that it might have some relationship with the recent slowdown of the global warming (e.g., Easterling and Wehner 2009), the associated changes in the tropical air-sea system (e.g., Tokinaga et al. 2012; England et al. 2014; Zheng et al. 2015; Zhang et al. 2016), and the decadal variations of the East Asian monsoon (e.g., Yuan and Chen 2013; Zhang 2015).

\section{Summary}

Based on daily mean precipitation dataset from 2479 stations in China and the start and end dates of the first rainy season (FRS) over South China defined and monitored by CMA (see section 2 for details of the definition), this study investigates the interannual variations of the FRS precipitation over South China and its mechanism. In contrast to previous studies that define the FRS on the basis of monthly mean data, this study defines the FRS in the daily sense as the period between the start and end dates of the FRS (Fig. 2a). In this way, the length of the FRS varies from year to year, with the average length of 90 days spanning from 6 April to 4 July. Although the FRS only takes approximately $25 \%$ of the length of a year, it contributes over $40 \%$ of the annual precipitation in South China and adjacent regions (Fig. 3), indicating its importance for the hydrological cycle in South China.

The FRS precipitation over South China exhibits strong interannual variations but does not show significant long-term trend. Composite analyses reveal that the total precipitation during wet FRS years could be 


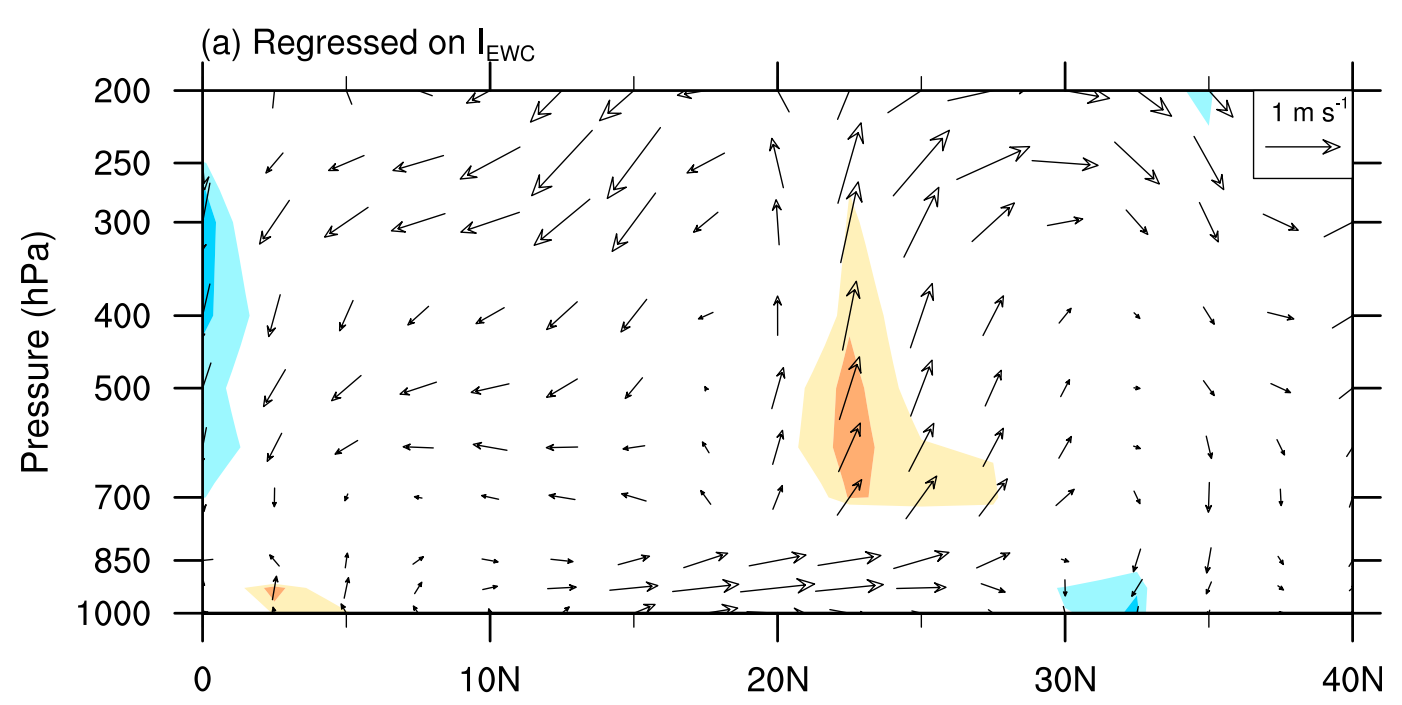

(b) Regressed on -I $\mathrm{WP}$

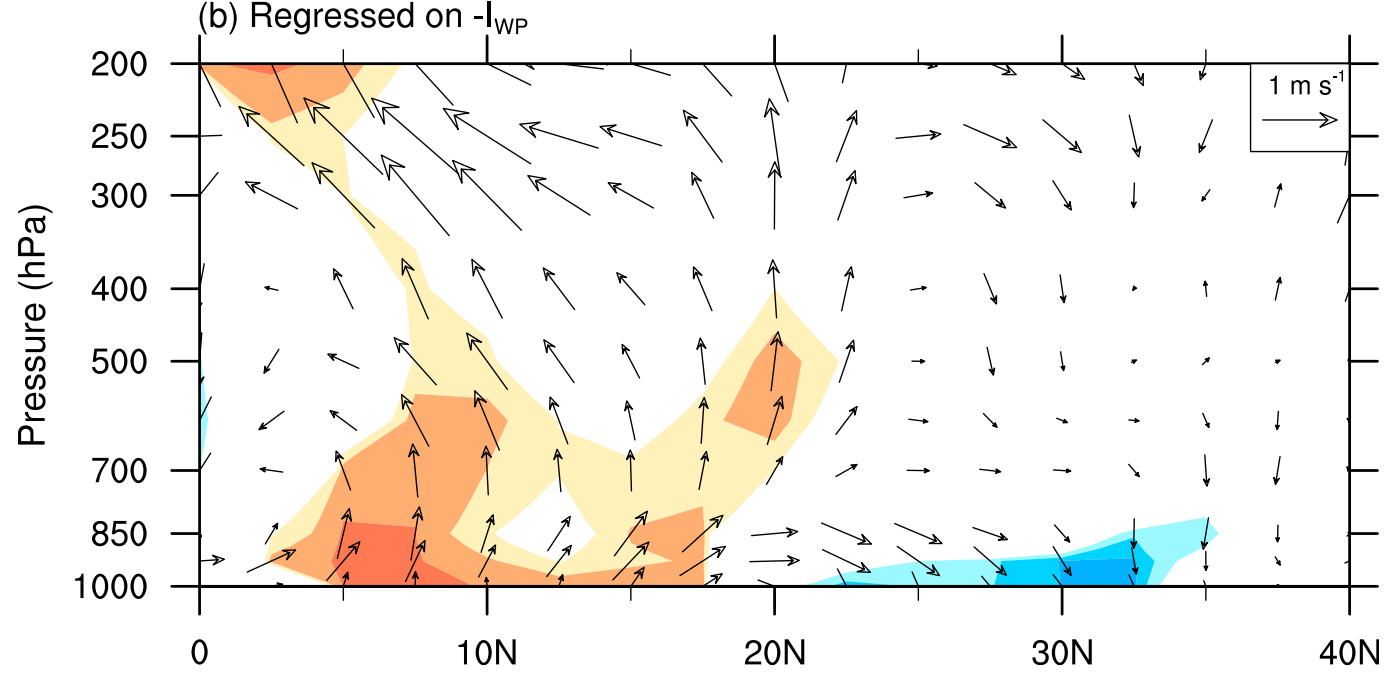

FIG. 14. Regression of meridional circulation averaged over $110^{\circ}-120^{\circ} \mathrm{E}$ during the FRS onto the normalized MAM mean (a) $I_{\text {EWC }}$ and (b) negative $I_{\mathrm{WP}}$. Dark, middle, and light shading indicate the $99 \%, 95 \%$, and $90 \%$ confidence levels based on two-tailed Student's $t$ test, respectively. The vertical velocity is multiplied by a factor of 500 for visual purpose.

twice as much as that during dry FRS years over South China (Fig. 5). Compared with those in dry FRS years, both the upper-tropospheric westerly jet stream situated at approximately $35^{\circ}-40^{\circ} \mathrm{N}$ and the prevailing tropical easterly winds are weakened in wet FRS years. As a result, the background anticyclonic shear between them is weakened, leading to a southwestward shift of the western Pacific subtropical high (Figs. 6a-c). The resultant tropospheric southwesterly wind anomalies facilitate enhanced water vapor transport and convergence toward South China, on the one hand (Fig. 7b) and anomalous warm advection toward South China, on the other hand (Fig. 6e). Both the moisture transport and the warm advection are stronger in the lower than in the middle troposphere, so this configuration increases the lower-tropospheric convective instability (Fig. 6f), leads to intensified ascending motion over South China (Fig. 8), and provides favorable large-scale circulations for abundant FRS precipitation. Here, the role of the tropospheric temperature advection is especially emphasized because the thermal advection is important to shape the spatial pattern of the anomalous vertical motion over South China (Fig. 9c) besides its abovementioned effects to destabilize the atmosphere. Moreover, the warm advection together with enhanced moisture transport could trigger local positive feedbacks between ascending motion and precipitation. The resultant release of latent heat serves as an important 

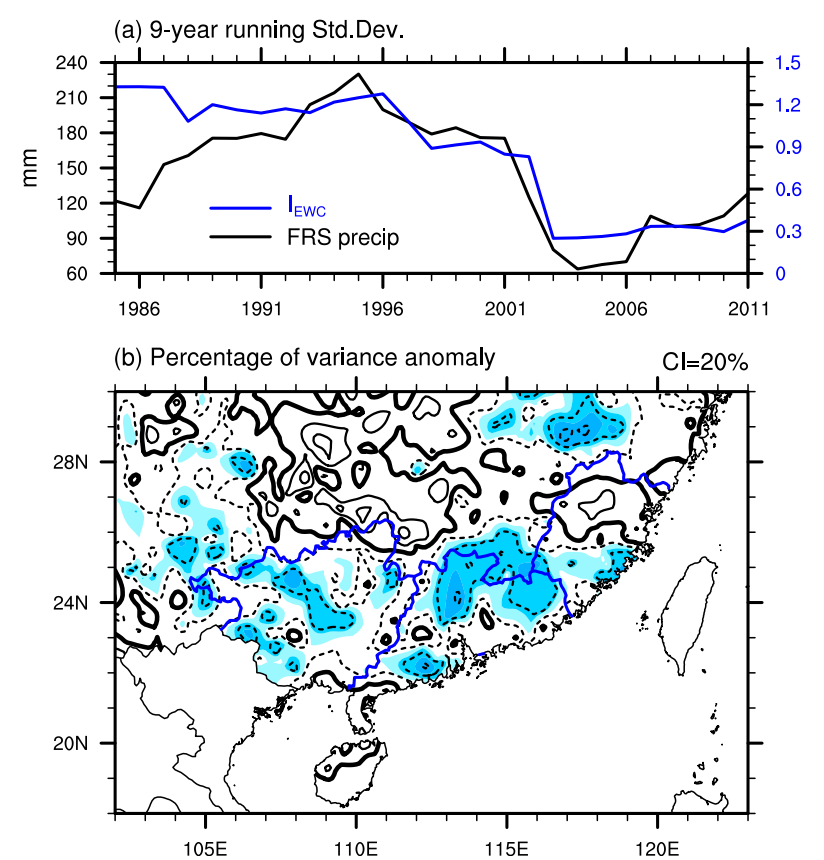

FIG. 15. (a) The running standard deviation of the FRS precipitation index (black) and MAM mean $I_{\mathrm{EWC}}$ (blue) with a 9-yr window. (b) Differences of the FRS precipitation's variance between $2000-15$ and 1981-99 periods divided by the FRS precipitation's variance calculated from the period 1981-2010. Contour intervals are $20 \%$. Zero contours are bolded, and contours with negative values are dashed. Dark, middle, and light shading indicate the $99 \%, 95 \%$, and $90 \%$ confidence levels based on $F$ test. Blue lines indicate the boundaries of Fujian, Guangdong, and Guangxi Provinces.

source of diabatic heating and contributes substantially to the anomalous ascending motion that accounts for the variations of the FRS precipitation (Fig. 9d).

An east-west SST dipole anomaly in the tropical Pacific that is different from ENSO is found to be closely related the interannual variations of the FRS precipitation over South China (Fig. 10). The simultaneous presence of colder-than-normal SST in the tropical western Pacific and warmer-than-normal SST in the tropical eastern Pacific would weaken the background Walker circulation significantly (Fig. 13a). The associated descending anomalies in the tropical western $\mathrm{Pa}$ cific would suppress convection and excite an anomalous anticyclone near Philippines in the lower troposphere via the Matsuno-Gill-type Rossby wave response (Fig. 13b). It enhances water vapor transport (Fig. 13c) and ascending motion (Fig. 14a) over South China, facilitating abundant FRS precipitation. Compared with previous studies that consider the SST over the western Pacific alone, we suggest that the SST dipole explains much larger interannual variance of the FRS precipitation (Fig. 12) and creates more favorable moisture and dynamical environment for altered FRS precipitation (Figs. 13 and 14). Therefore, the SST dipole may be used as an efficient indicator in the operational predictions of the FRS precipitation over South China. Further inspection reveals that the interannual variability of the SST dipole is weakened after the year 2000 (Figs. 4 and 16) and that the interannual variability of the FRS precipitation is weakened accordingly (Fig. 15). This decadal change is consistent with the overall weakening of air-sea coupling in the tropical Pacific Ocean (Hu et al. 2013; Kumar and $\mathrm{Hu}$ 2014), but its cause is not clear and deserves further investigation in the future.

\section{Discussion}

In this study, the start and end dates of the FRS are defined and archived by the National Climate Center of the CMA (National Climate Center 2013), and the end date of the FRS is 4 July on average (Fig. 2). One may be surprised by this result because it is generally thought that the period after mid-June is mei-yu season, during which the main rain belt is located along the Yangtze River (e.g., Ding and Chan 2005). To examine this seeming contradiction, the daily mean precipitation is examined for three periods: 6 April14 June, 15 June-4 July, and 5 July-15 July (Fig. 17). In the early stage of the FRS (6 April-14 June), the intensity of precipitation decreases from South China toward the Yangtze River and farther inland (Fig. 17a). In the late stage of the FRS (15 June4 July) that is usually considered as the mei-yu season (e.g., Ding and Chan 2005), the northern and southern precipitation maxima show a splitting tendency compared with those in the early stage, as indicated by a slight northward movement of the maximum over the northwestern portion of Fujian Province (Fig. 17b). However, the pattern of precipitation remains almost the same with precipitation maximums being located south of the Yangtze River (Figs. 17a,b). In contrast, the pattern of precipitation is totally different after the FRS ends, and a clearly isolated rain belt is observed along the Yangtze River (Fig. 17c). The higher similarity between Figs. 17a and $17 \mathrm{~b}$ than that between Figs. $17 \mathrm{~b}$ and $17 \mathrm{c}$ suggests that the period from 15 June to 4 July should belong to the FRS in the climatological mean sense. This argument is also supported by previous studies that define the FRS as April, May, and June (Chi et al. 2005; Qiang and Yang 2008).

Despite the above results, we cannot reject that the period 15 June-4 July belongs to the mei-yu season because there is indeed a northward shift, albeit very 
(a) Percentage of variance anomaly, MAM
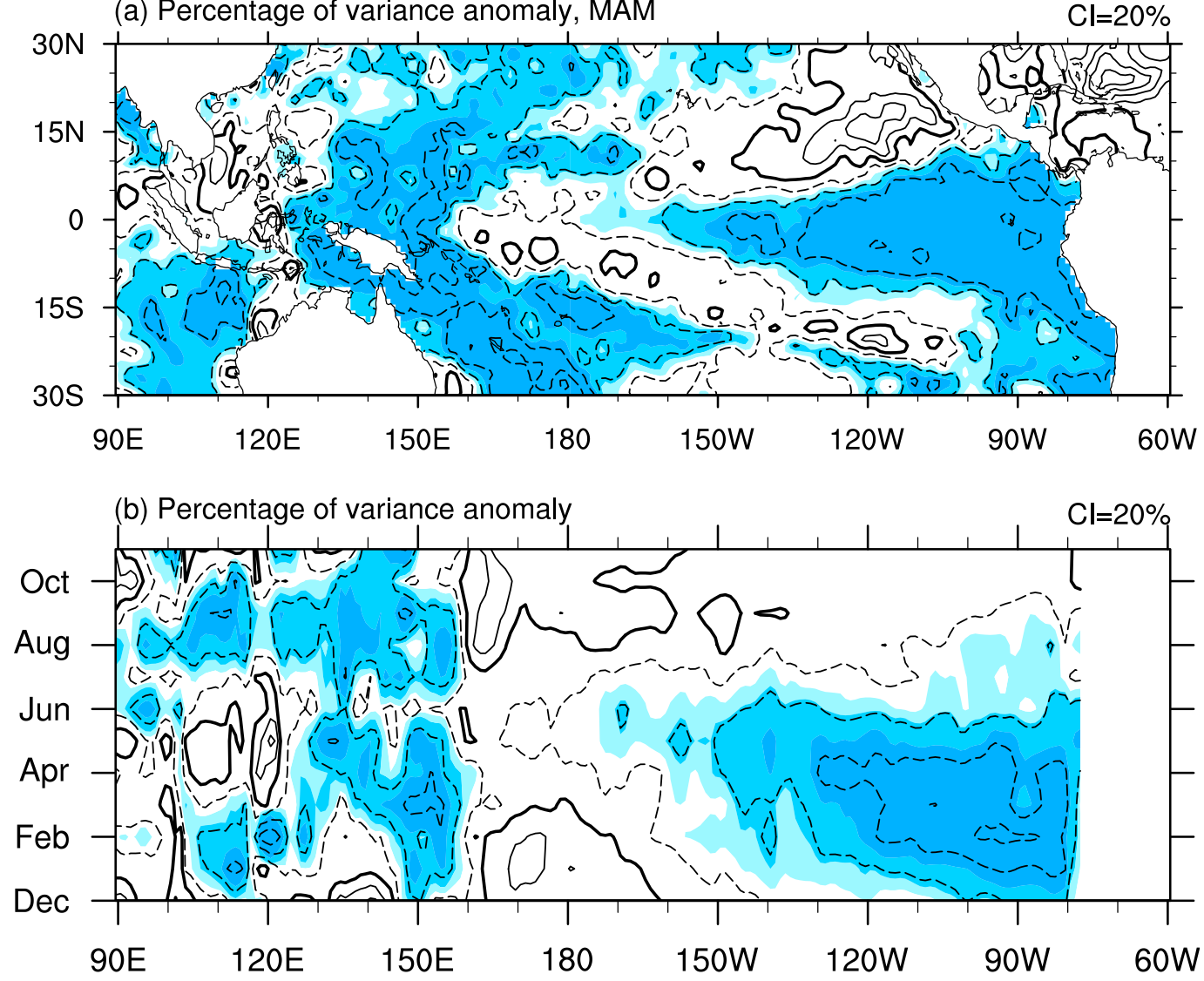

FIG. 16. As in Fig. 15b, but for (a) the MAM mean SST and (b) monthly tropical SST averaged over $7.5^{\circ} \mathrm{S}-7.5^{\circ} \mathrm{N}$. Contour intervals are $20 \%$. Zero contours are bolded, and contours with negative values are dashed. Dark, middle, and light shading indicate the $99 \%, 95 \%$, and $90 \%$ confidence levels based on the $F$ test.

slight, of precipitation maximum during this period (Fig. 17b), not to mention many studies that define the start of mei-yu season as mid-June (e.g., Ding and Chan 2005, and references therein). In light of these controversial studies (e.g., Ding and Chan 2005; Chi et al. 2005; Qiang and Yang 2008; National Climate Center 2013) and the evidence we have (Fig. 17), it is inferred that the start of the mei-yu season along the Yangtze River may not correspond to the end of the FRS over South China. Their plausible coexistence reflects the complexity of the East Asian summer monsoon, which deserves careful investigation in the future.

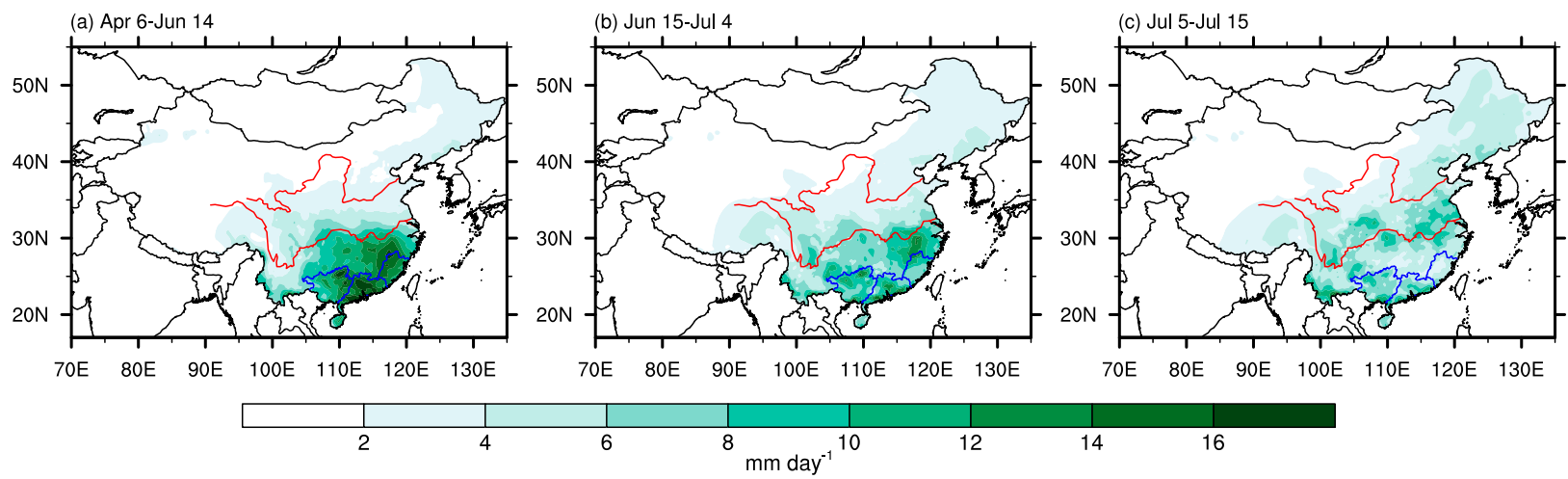

FIG. 17. The climatology of daily mean precipitation during the period (a) 6 Apr-14 Jun, (b) 15 Jun-4 Jul, and (c) 5-15 Jul. Shading interval is $2 \mathrm{~mm} \mathrm{day}^{-1}$. Red lines indicate the Yellow River and Yangtze River. Blue lines indicate the boundaries of Fujian, Guangdong, and Guangxi Provinces. 
A distinct difference of this study from previous ones is that both precipitation and atmospheric circulations of the FRS are defined on the basis of daily data, and the length of the FRS varies year to year. A natural question is to what extent these results are different from previous ones that are based on monthly mean data. To address this issue, we used the mean of April-June to represent the FRS and repeated all the analyses. It reveals that the results remain principally similar, although some signals are weaker especially with regard to the zonal SST dipole (not shown). On the one hand, this result is expected because the FRS defined on the basis of daily data overlaps largely with April, May, and June (Fig. 2a). On the other hand, the better results and clearer signals shown in this study suggest the advantage and necessity of defining the FRS on the basis of daily data.

Given the varying length of the FRS, another question may arise whether the amount of the FRS precipitation is related to the length or the start and end date of the FRS. Preliminary analysis indicates that they are closely linked to each other. The correlation coefficient between the FRS precipitation index and the length of the FRS (start date of the FRS, end date of the FRS) is 0.74 $(-0.55,0.63)$ for the period 1981-2015, far exceeding the $99.9 \%$ confidence level. It suggests that more FRS precipitation over South China is expected if the FRS starts early, ends late, or lasts long. A probably more interesting phenomenon is that the length of the FRS is tightly related to the start date of the FRS. The correlation coefficient between them is -0.87 for the period 1981-2015. It implies that the length of the FRS could be well predicted once the FRS begins, and this information may be useful in operational predictions.

Last but not least, the composite between wet and dry FRS cases and linear regression onto SST indices are used in this study, and these methods assume that the anomalies of variables are symmetric in wet and dry FRS cases and that the atmospheric responses to SST anomalies are linear. In the real climate, however, perfect linearity and symmetry can rarely be observed. A close inspection suggests that the results reported in this study are only quasi-linear, and that the wet FRS case fits the proposed anomalies and mechanism better than the dry FRS case does. For example, the SST dipole is stronger and more significant in wet FRS case than in dry FRS case. It implies that the predictability of sufficient precipitation (flooding) may be better than that of deficient precipitation (drought) during the FRS over South China. Meanwhile, the positive feedback between precipitation and circulation is also stronger in the wet FRS case than in the dry FRS case. It might be related to the asymmetric atmospheric responses to diabatic heating over South China, which deserves further investigation in the future.

Acknowledgments. We thank the three anonymous reviewers for their constructive comments that led to improvements to the manuscript. This work was supported by the National Key Technology Support Program of China (2015BAC03B04, 2013CB430203) and the National Natural Science Foundation of China (41422501, 41661144016). Part of this work was done during a visit of WG to the NOAA/NCEP Climate Prediction Center.

\section{REFERENCES}

Cai, X., Y. Wang, and J. Xu, 2002: Diagnostic analysis on impact of convective activity anomalies over tropical on flood/drought during the first rainy season in south China. J. Trop. Meteor., 18, 157-164.

Chan, J. C. L., and W. Zhou, 2005: PDO, ENSO and the early summer monsoon rainfall over south China. Geophys. Res. Lett., 32, L08810, doi:10.1029/2004GL022015.

Chang, Y., J. He, Y. Liu, and P. Liang, 2006: Features of moisture transport in pre-summer flood season of drought and flood years over south China. Plateau Meteor., 25, 1064-1070.

Chen, L., Q. Zhu, H. Luo, J. He, M. Dong, and Z. Feng, 1991: East Asian Monsoon. China Meteorological Press, 362 pp.

Chen, W., L. Wang, Y. K. Xue, and S. F. Sun, 2009: Variabilities of the spring river runoff system in east China and their relations to precipitation and sea surface temperature. Int. J. Climatol., 29, 1381-1394, doi:10.1002/joc.1785.

Chi, Y., J. He, and Z. Wu, 2005: Features analysis of the different precipitation periods in the pre-flood season in south China. J. Nanjing Inst. Meteor., 28, 163-171.

Deng, L., and Q. Wang, 2002: On the relationship between precipitation anomalies in the first raining season (April-June) in southern China and SST over offshore waters in China. J. Trop. Meteor., 18, 45-55.

Ding, Y., 2007: The variability of the Asian summer monsoon. J. Meteor. Soc. Japan, 85B, 21-54, doi:10.2151/jmsj.85B.21.

, and J. C. L. Chan, 2005: The East Asian summer monsoon: An overview. Meteor. Atmos. Phys., 89, 117-142, doi:10.1007/ s00703-005-0125-z.

Easterling, D. R., and M. F. Wehner, 2009: Is the climate warming or cooling? Geophys. Res. Lett., 36, L08706, doi:10.1029/ 2009GL037810.

England, M. H., and Coauthors, 2014: Recent intensification of wind-driven circulation in the Pacific and the ongoing warming hiatus. Nat. Climate Change, 4, 222-227, doi:10.1038/ nclimate2106.

Feng, J., W. Chen, C. Y. Tam, and W. Zhou, 2011: Different impacts of El Niño and El Niño Modoki on China rainfall in the decaying phases. Int. J. Climatol., 31, 2091-2101, doi:10.1002/ joc. 2217 .

Gill, A. E., 1980: Some simple solutions for heat-induced tropical circulation. Quart. J. Roy. Meteor. Soc., 106, 447-462, doi:10.1002/qj.49710644905.

Gu, W., L. Wang, W. Li, L. Chen, and C. Sun, 2015: Influence of the tropical Pacific east-west thermal contrast on the autumn 
precipitation in south China. Int. J. Climatol., 35, 1543-1555, doi:10.1002/joc.4075.

Hayashi, Y., 1982: Confidence intervals of a climatic signal. J. Atmos. Sci., 39, 1895-1905, doi:10.1175/1520-0469(1982)039<1895: CIOACS $>2.0 . \mathrm{CO} ; 2$.

Hu, K., G. Huang, R. Wu, and L. Wang, 2017: Structure and dynamics of a wave train along the wintertime Asian jet and its impact on East Asian climate. Climate Dyn., doi:10.1007/ s00382-017-3674-1, in press.

Hu, Z.-Z., A. Kumar, H.-L. Ren, H. Wang, M. L'Heureux, and F.-F. Jin, 2013: Weakened interannual variability in the tropical Pacific Ocean since 2000. J. Climate, 26, 2601-2613, doi:10.1175/JCLI-D-12-00265.1.

Huang, R. H., and Y. Wu, 1989: The influence of ENSO on the summer climate change in China and its mechanism. $A d v$. Atmos. Sci., 6, 21-32, doi:10.1007/BF02656915.

- J. J. Chen, L. Wang, and Z. Lin, 2012: Characteristics, processes, and causes of the spatio-temporal variabilities of the East Asian monsoon system. Adv. Atmos. Sci., 29, 910-942, doi:10.1007/s00376-012-2015-x.

Kalnay, E., and Coauthors, 1996: The NCEP/NCAR 40-Year Reanalysis Project. Bull. Amer. Meteor. Soc., 77, 437-471, doi:10.1175/1520-0477(1996)077<0437:TNYRP>2.0.CO;2.

Kosaka, Y., S.-P. Xie, and H. Nakamura, 2011: Dynamics of interannual variability in summer precipitation over East Asia. J. Climate, 24, 5435-5453, doi:10.1175/2011JCLI4099.1.

Kumar, A., and Z.-Z. Hu, 2014: Interannual and interdecadal variability of ocean temperature along the equatorial Pacific in conjunction with ENSO. Climate Dyn., 42, 1243-1258, doi:10.1007/s00382-013-1721-0.

National Climate Center, 2013: Monitoring of the first rainy season of south China. National Climate Center Rep., 17 pp.

Qiang, X., and X. Yang, 2008: Onset and end of the first rainy season in south China. Chin. J. Geophys., 51, 1333-1345.

—, and — 2013: Relationship between the first rainy season precipitation anomaly in south China and the sea surface temperature anomaly in the Pacific. Chin. J. Geophys., 56, 2583-2593.

Rayner, N. A., and Coauthors, 2003: Global analyses of sea surface temperature, sea ice, and night marine air temperature since the late nineteenth century. J. Geophys. Res., 108, 4407, doi:10.1029/2002JD002670.

Sun, J., and S. Zhao, 2000: A diagnosis and simulation study of a strong heavy rainfall in south China. Chin. J. Atmos. Sci., 24, 381-392.

Tao, S. Y., and L. X. Chen, 1987: A review of recent research on the East Asian summer monsoon in China. Monsoon Meteorology, C.-P. Chang and T. N. Krishnamurti, Eds., Oxford University Press, 60-92.

Tokinaga, H., S.-P. Xie, C. Deser, Y. Kosaka, and Y. M. Okumura, 2012: Slowdown of the Walker circulation driven by tropical Indo-Pacific warming. Nature, 491, 439-443, doi:10.1038/ nature11576.

Wang, B., 2006: The Asian Monsoon. Springer, 845 pp.

- R. Wu, and X. Fu, 2000: Pacific-East Asian teleconnection: How does ENSO affect East Asian climate? J. Climate, 13, 15171536, doi:10.1175/1520-0442(2000)013<1517:PEATHD>2.0.CO;2.
Wang, D., R. Xia, and Y. Liu, 2011: A preliminary study of the flood-causing rainstorm during the first rainy season in south China in 2008. Acta Meteor. Sin., 69, 137-148.

Wang, L., and W. Gu, 2016: The eastern China flood of June 2015 and its causes. Sci. Bull., 61, 178-184, doi:10.1007/ s11434-015-0967-9.

Wu, R., Z. Z. Hu, and B. Kirtman, 2003: Evolution of ENSO-related rainfall anomalies in East Asia. J. Climate, 16, 3742-3758, doi:10.1175/1520-0442(2003)016<3742:EOERAI >2.0.CO;2.

Wu, Z., Z. Jiang, and J. He, 2006: The comparison analysis of flood and drought and drought features among the first flood period in south China, meiyu period in the Yangtze River and the Huaihe River valleys and rainy season in north China in the last 50 years. Chin. J. Atmos. Sci., 30, 391-401.

Yao, S., Q. Huang, and C. Zhao, 2016: Variation characteristics of rainfall in the pre-flood season of south China and its correlation with sea surface temperature of Pacific. Atmosphere, 2016, 5, doi: $10.3390 /$ atmos 7010005 .

Yuan, F., and W. Chen, 2013: Roles of the tropical convective activities over different regions in the earlier onset of the South China Sea summer monsoon after 1993. Theor. Appl. Climatol., 113, 175-185, doi:10.1007/s00704-012-0776-x.

—_, K. Wei, W. Chen, S. K. Fong, and K. C. Leong, 2010: Temporal variations of the frontal and monsoon storm rainfall during the first rainy season in south China. Atmos. Oceanic Sci. Lett., 3, 243-247, doi:10.1080/ 16742834.2010.11446876.

_- W. Chen, and W. Zhou, 2012: Analysis of the role played by circulation in the persistent precipitation over south China in June 2010. Adv. Atmos. Sci., 29, 769-781, doi:10.1007/ s00376-012-2018-7.

Zhang, J., T. Zhou, R. Yu, and X. Xin, 2009: Atmospheric water vapor transport and corresponding typical anomalous spring rainfall patterns in China. Chin. J. Atmos. Sci., 33, 121-134.

Zhang, J.-Y., L. Wang, S. Yang, W. Chen, and J. Huangfu, 2016: Decadal changes of the wintertime tropical tropospheric temperature and their influences on the extratropical climate. Sci. Bull., 61, 737-744, doi:10.1007/s11434-016-1054-6.

Zhang, R. H., 2015: Changes in East Asian summer monsoon and summer rainfall over eastern China during recent decades. Sci. Bull., 60, 1222-1224, doi:10.1007/ s11434-015-0824-x.

_ , and A. Sumi, 2002: Moisture circulation over East Asia during El Niño episode in northern winter, spring and autumn. J. Meteor. Soc. Japan, 80, 213-227, doi:10.2151/ jmsj.80.213.

_, _ and M. Kimoto, 1996: Impact of El Niño on the East Asian monsoon: A diagnostic study of the '86/87 and ' $91 / 92$ events. J. Meteor. Soc. Japan, 74, 49-62, doi:10.2151/ jmsj1965.74.1_49.

- - , and - 1999: A diagnostic study of the impact of El Niño on the precipitation in China. Adv. Atmos. Sci., 16, 229241, doi:10.1007/BF02973084.

Zheng, F., W. Zhang, J. Yu, and Q. Chen, 2015: A possible bias of simulating the post-2000 changing ENSO. Sci. Bull., 60, 18501857, doi:10.1007/s11434-015-0912-y. 